\title{
AVALIAÇÃo In VIVo dos Efeitos Genotóxicos/Citotóxicos De DISJUNTORES de HAAS SOBRe CÉlULAS dA MUCOSA BUCAL, PELA ANÁLISE de MiCRONÚCleOS
}

\author{
Dissertação de Mestrado apresentada à Faculdade \\ de Odontologia de Ribeirão Preto da Universidade de \\ São Paulo, como parte dos requisitos para obtenção \\ do grau de Mestre em Ciências. \\ Programa: Odontopediatria \\ Área de Concentração: Odontopediatria
}

Orientador: Prof. Dr. Paulo Nelson Filho 


\section{AUTORIZAÇÃO PARA REPRODUÇÃO}

Autorizo a reprodução e divulgação total ou parcial deste trabalho, por qualquer meio convencional ou eletrônico, para fins de estudo e pesquisa, desde que citada a fonte.

FICHA CATALOGRÁFICA

Cunha, Arthur da Silva

Avaliação in vivo dos efeitos genotóxicos/citotóxicos de Disjuntores de Haas sobre células da mucosa bucal, pela análise de micronúcleos. Ribeirão Preto, 2017.

71p. : il. ; $30 \mathrm{~cm}$

Dissertação de Mestrado apresentada à Faculdade de Odontologia de Ribeirão Preto da Universidade de São Paulo, como parte dos requisitos para obtenção do grau de Mestre em Ciências.

Orientador: Nelson-Filho, Paulo

1. Expansão Maxilar; 2. Testes para Micronúcleo; 3. Genotoxicidade; 4. Citogenética. 
Cunha, AS. Avaliação in Vivo dos Efeitos Genotóxicos/Citotóxicos de Disjuntores de Haas Sobre Células da Mucosa Bucal, Pela Análise de Micronúcleos.

Dissertação de Mestrado apresentada à Faculdade de Odontologia de Ribeirão Preto da Universidade de São Paulo, como parte dos requisitos para obtenção do título de Mestre em Ciências.

Data da defesa:<smiles>CI=CI</smiles>

\section{BANCA EXAMINADORA}

Prof(a). Dr(a).

Instituição:

Julgamento: Assinatura:

$\operatorname{Prof}(a) \cdot \operatorname{Dr}(a)$

Instituição:

Julgamento: Assinatura:

Prof(a). Dr(a).

Instituição:

Julgamento: Assinatura:

$\operatorname{Prof}(a) \cdot \operatorname{Dr}(a)$.

Instituição:

Julgamento: Assinatura: 



\section{Arthur Cunha da Silva}

Dados CuRRICULARES

Nascimento

Filiação

2006-2010

2009-2009

2011-2012

2012-2015

2012-2014

2012-2014

2014-2016

2015-2017

2017-2017
30 de outubro de 1986 - Belém/PA

Paulo Roberto Pinheiro da Silva

Valdéa de Nazaré Cunha da Silva

Graduação em Odontologia

Centro Universitário do Estado do Pará, CESUPA

Atualização em Cirurgia Oral da ABO

Associação Brasileira de Odontologia / Pará, ABO/PA

Capacitação em Ortodontia com Ênfase em Diagnóstico

Faculdade de Odontologia da Universidade Federal do Pará - UFPA/PA

Especialização em Ortodontia

Fundação Odontológica de Ribeirão Preto - FUNORP

Extensão Universitária em Centro de Formação de Recursos Humanos Especializados no Atendimento Odontológico a Pacientes Especiais

Departamento de Clínica Infantil - FORP/USP

Extensão Universitária em Odontologia Preventiva e Interceptadora

Departamento de Clínica Infantil - FORP/USP

Extensão Universitária em "Tratamentos Orto-Cirúrgico em Pacientes Adultos"

Faculdade de Odontologia de Ribeirão Preto - FORP/USP

Pós-Graduação - nível mestrado

Área de concentração: Odontopediatria

Faculdade de Odontologia de Ribeirão Preto - USP

Orientador: Prof. Dr. Paulo Nelson Filho

Bolsa: $\mathrm{CNPq}$

Extensão Universitária: Estudante Visitante em Universidade de Pittsburgh, PA, Estados Unidos 

Primeíramente a Deus, por sempre estar ao meu lado em todos os momentos. Sem a fé em Sua existência nada tería sentido e nada sería possivel. Obrigado por me mostrar o caminho, não deixando o ego falar maís alto e tratando ao próximo sempre com respeito como dígnos filhos do mesmo paí.

Aos meus país, Paulo e Valdéa, pelo total apoio e suporte dedicados em anos de puro trabalho. Com muita fé, obtiveram sucesso em disponibilizar toda a base para a criação, educação e principalmente amor a seus filhos. Seus valores e ensinamentos moldaram minha personalidade e caráter. Sou eternamente grato. Obrigado por me apoiarem em todas as minhas decisões tomadas até momento. Sem essa base familiar enraizada, não tería condições de prosperar e realizar este trabalho.

Às minhas irmãs, Paula e Luciana, por sempre me servirem de exemplo e inspiração para continuar em busca de meus sonhos. Suas determinaçôes me motivam e inspiram a nunca perder o foco de minhas metas. 



\section{Agradecimento Especial}

Ao meu orientador Prof. Dr. Paulo Nelson-Filho.

Me considero um aluno de sorte por ter sido orientado por uma grande pessoa. Tentei sempre extraír ao máximo os exemplos demonstrados no día-a-día. Nada é por acaso e não é ao acaso que hoje esta Instituição de Ensino é uma das mais respeitadas e influentes no meío cientifico. Nos minimos detalhes pude presenciar a grandeza de um profissional dedicado, competente, ético e compromissado em realizar um trabalho de excelêncía. Espero obter força e maturidade para alcançar algum día esta ideologia de vida e trabaltho com a qual tanto me identifico e respeito. 

À Universidade de São Paulo, na pessoa do atual reitor, Prof. Dr. Marco Antonio Zago, e do Vice-reitor Prof. Dr. Vahan Agopyan.

À Faculdade de Odontología de Ríbeirão Preto da Universidade de São Paulo, na pessoa da Diretora, Profa. Dra. Léa Assed Bezerra da Silva e do Vice-Diretor Prof. Dr. Arthur Belem Novaes Júnior.

A Profa. Dra. Erika Calvano Küchler, por ter confiado em meu trabalho e proporcionado uma das experiências mais marcantes, até o momento, que foi poder passar alguns meses na Universidade de Pittsburgh, PA, Estados Unidos. Fico muito feliz que o fruto de nosso trabalho mútuo, tenha surgído uma bela amizade ao qual pretendo manter. Sua dedicação em me fazer enxergar o caminho do aprendizado foi fundamental para o meu amadurecimento.

Ao Prof. Dr. Fabio Lourenço Romano, a quem eu não cansarei de agradecer por seus ensinamentos e dedícação usufruído ao longo desses anos. Considero um exemplo de profissional e sobretudo de ser humano. Sua ideología e caráter me inspiram até hoje e me fortalecem em busca de meus objetivos. Precisamos de um número maior de pessoas com essas características para o bem não só de uma instituição, mas sobretudo de nossa sociedade. Sua paciêncía e humildade são louváveís.

À Profa. Dra. Miran Aiko Nakane Matsumoto, com quem eu tive o prazer de trabalhar (aprender) durante todos esses anos. Foi a professora que teve maior influência 
em minha prática clinica. Por saber de meus objetívos desde a época da Especialização, me ensinou, me orientou e principalmente me instigou com a finalidade de extraír o máximo de meu esforço em me tornar um profissional melhor a cada dia.

Ao Prof. Dr. Adilson Tomasin, por ser uma pessoa de luz inabalável. Foi o primeiro professor a me proporcionar conviç̧ão de minhas atitudes como aluno, me encorajando a seguir sempre em frente.

Ao Prof. Dr. José Tarcisio Lima Ferreíra, por seus ensinamentos e conselhos desde a época de especialização. Sempre me mostrando a maneira correta de solucionar as intercorrências profíssionaís e da vida.

Às Profas. Dras. Catharina Satie Takahashi e Elza T'iemi Sakamoto Hojo, pelo suporte físico do laboratório, onde nada faltou para realização deste trabaltho e pelo suporte cientifico, com anos de conhecimento e dedicação em repassar tal experiência para seus alunos. Agradeço também ao suporte emocional, pelo fato de sempre me sentír seguro e à vontade no laboratório para poder realizar esta pesquisa.

Aos Professores do Departamento de Clínica Infantil da FORP/USP, Prof. Dr. Alberto Consolaro, Profa. Dra. Aldevina Campos de Freitas, Profa. Dra. Alexandra Mussolino de Queiroz, Profa. Dra. Andiara De Rossi Daldegan, Prof. Dr. Fabrícío Kitazono de Carvalho, Profa. Dra. Kranya Victoría Díaz Serrano, Profa. Dra. Léa Assed Bezerra da Silva, Profa. Dra. María Cristina Borsato, Profa. Dra. Raquel Assed Bezerra 
Segato, Profa. Dra. María da Conceição Pereira Saraíva, por toda organização e dedícação de anos e anos de trabalho, gerando docentes hoje inseridos em várias instituições nacionaís.

Aos funcionários do Departamento da Clínica Infantil, Dra. Carolina Torres Mantovani, Prof. Dr. Francisco Wanderley Garcia de Paula e Silva, Dra. Marilía Pacifico Lucísano, Carmo Eurípedes T'erra Barreto (ín Memoriam), Marco Antônío dos Santos, Fatima Aparecida Jacinto Daniel, Filomena Leli Placciti, Matheus Morelli Zanela, Benedita Rodrigues Viana, por todo carinho e suporte nesses anos. Muito obrígado!

Aos professores do curso de especialização em ortodontía, Prof. Dr. Ademar Valente (in Memoriam), Profa. Dra. Carla Enoki Itikawa, Profa. Dra. Marcela Crístína Damião Andruciolli, Marcelo Antônio Mestriner, ainda hoje exercem influência díreta e indíreta em minhas atitudes ortodônticas. Serei eternamente grato.

Aos colegas de turma do mestrado em Odontopediatría Alessandra Parreira Menino, Ana María Guerra Costa, Ana Paula Dias Moreno, Guido Marañon Vasques, Letícía Sgarby Pinto, Mariana Trevizan, Mariana Umekita Shirozaki, Thaíse Taira, com quem tive o prazer de compartilhar esses anos de aprendizado. Cada um teve papel importante em minha caminhada. Me sinto um felizardo em ter convivido com colegas com formas variadas de agir e pensar. $\mathcal{A}$ oportunidade de refletir e desenvolver novas maneiras de lidar com as diferentes sítuações que nos deparamos na vída é imensurável.

Às alunas da Pós-Graduação em Odontologia, Carolina Maschietto Pucinelli, Francine Lorencetti, Juliana Arid, Laura Bastos, Nicole Lima, Raquel Morelli e Thais Xavier, com quem tive o prazer de compartilhar algumas discíplinas e foram importantes na minha formação acadêmica. 
Aos meus colegas do Laboratórío Ana Paula, Danilo Xavier, Leonardo Franchi e Willian Castillo, obrigado por me acolherem no grupo e estarem sempre dispostos a ajudar. Conhecer cada um de vocês foi uma grande e excelente surpresa. Minhas expectatívas em compartilhar conhecimento fora de meu departamento original supriu minhas expectativas, graças ao convívío que tíve com vocês.

À Rosemary Alves, secretáría do curso de Especialização em Ortodontía, a quem sou suspeito de falar. São anos do maís gratíficante convivio, fazendo-me lembrar a relação com meus entes familiares. Muito obrigado por toda a contríbuição e disposição desde que cheguei a Ríbeirão Preto.

À Nilza Letícía Magalhães, técnica do laboratório do Departamento da Clínica Infantil, resumo de simpatía e simplicidade. Infelizmente só trabalhamos juntos no final de minha pesquisa, mas já conhecia sua pessoa e sabia que sería extremamente gratificante quando tivesse a oportunidade de dividir o mesmo ambiente de trabalho.

Ao Luiz Augusto Costa Junior, técnico do laboratório da Faculdade de Filosofía, Ciências e Letras de Ríbeirão Preto, agradeço por todo o apoío que tíve desde os meus primeiros passos em laboratório. Consegui desenvolver a habilidade necessáría, muito em função da sua dedicação em solucionar minhas dúvídas e corrígír meus erros.

Ao CNPPq, pela bolsa concedida para a realização desta pesquísa. 


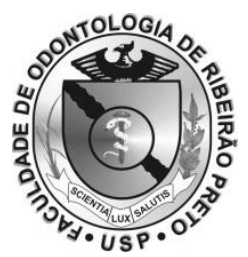

O referido Projeto foi desenvolvido nos Laboratórios de "Ortodontia", "Histologia" e "Biologia Molecular e Cultura de Células" do Departamento de Clínica Infantil da Faculdade de Odontologia de Ribeirão Preto - USP, e no Laboratório de "Citogenética e Mutagênese" da Faculdade de Filosofia, Ciências e Letras de Ribeirão Preto - USP.

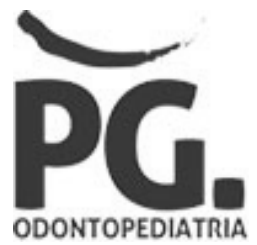





\section{RESUMO}

Cunha AS. Avaliação in vivo dos efeitos genotóxicos e citotóxicos de disjuntores de Haas Sobre Células da Mucosa Bucal, pela análise de micronúcleos. Ribeirão Preto, 2017. 71p. Dissertação (Mestrado). Faculdade de Odontologia de Ribeirão Preto da Universidade de São Paulo.

O objetivo do presente estudo foi avaliar os efeitos genotóxicos/citotóxicos ocasionados por disjuntores de Haas em células epiteliais esfoliadas da mucosa bucal de pacientes submetidos a tratamento ortodôntico, por meio do ensaio de micronúcleos. Participaram do estudo 22 pacientes entre 06 a 12 anos de idade, de ambos os gêneros, que necessitaram de disjuntores de Haas para correção de mordida cruzada posterior. Foi efetuada a coleta de células epiteliais da mucosa da bochecha, por meio de raspagem suave com escova científica. As células foram coletadas antes (T0), um mês após a instalação do aparelho (T1) e 3 meses após o travamento dos disjuntores (T2). As células foram processadas para obtenção de lâminas, as quais foram coradas com o método de Feulgen/Fast Green para quantificação do número de células normais, cariolíticas, picnóticas, brotos nucleares, bi/trinucleadas e com a presença de micronúcleos, em microscospia de luz. Os resultados foram submetidos à analise estatistica por meio do teste ANOVA, seguido do pós-teste de Tukey. O nível de significância adotado foi de 5\%. Os resultados demonstraram que não houve diferença estatisticamente significante com relação à preença de micronúcleos, nos períodos avaliados $(p>0,05)$. Os brotos nucleares sofreram aumento em T1 ( $>0,05)$, com retorno aos níveis baseline em T2. Em relação às outras anormalidades (células cariolíticas, picnóticas e bi/trinucleadas), houve aumento significante em T1 e T2 $(p<0,0001)$. Concluindo, este estudo demonstrou que os disjuntores de Haas não ocasionaram aumento de micronúcleos em células da mucosa bucal. Entretanto, foram observadas aumento estatisticamente significante das células cariolíticas, picnóticas e bi/trinucleadas durante o tratamento, sugerindo possíveis efeitos citotóxicos.

Palavras-chave: Expansão Maxilar; Testes para Micronúcleos; Genotoxicidade; Citogenética. 



\begin{abstract}
Cunha AS. Genotoxic/cytotoxic in vivo effects of Haas appliance by micronucleus assay in exfoliated mucosal cells. Ribeirão Preto, 2017. 71p. Dissertação (Mestrado). Ribeirão Preto: Faculdade de Odontologia de Ribeirão Preto da Universidade de São Paulo.
\end{abstract}

The aim of the present study was to evaluate the genotoxic and cytotoxic effects caused by Haas appliance through micronuclei assay in buccal mucosa epithelial cells of patients submitted to orthodontic treatment. The study included 22 patients between 06 and 12 years of age, both genders, who required Haas appliance for correction of posterior crossbite. Epithelial cells from the cheek mucosa were collected performed by gentle scraping scientific toothbrush. The cells were collected before (T0), one month after the device was installed (T1) and 3 months after the appliance immobilization (T2). The cells were processed to obtain slides and Feulgen/Fast Green was used as staining method for counting the number of normal, karyolytic, pyknotic, nuclear buds, binucleated and micronucleus cells under light microscopy. The cellular abnormalities were evaluated with the parametric tests for comparison of the means by ANOVA test followed by the Tukey post-test. The significance level was $5 \%$. The results of this study showed that there were no statistically significant results for the micronuclei in the evaluated periods $(p>0,05)$. Nuclear buds increased in $T 1(p<0,05)$, returning to baseline levels in $T 2$. In relation to the other abnormalities (cariolytic, pyknotic and bi/trinucleated cells), there were a significant increase in T1 and T2 $(p<0.0001)$. In conclusion, this study demonstrated that Haas appliance did not cause micronuclei increase in cells of buccal mucosa. However, a statistically significant increase in cariolytic, pyknotic and bi/trinucleated cells were observed during treatment, suggesting possible cytotoxic effects.

Keywords: Palatal Expansion Technique; Micronucleus Tests; Genotoxicity; Cytogenetic 



\section{SUMÁRIO}



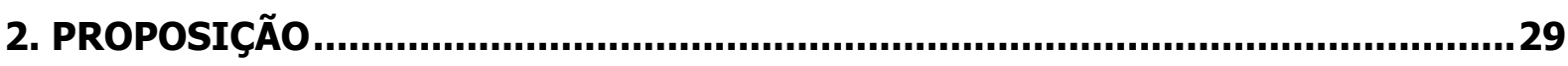

3. MATERIAL E MÉTODO.................................................................................33

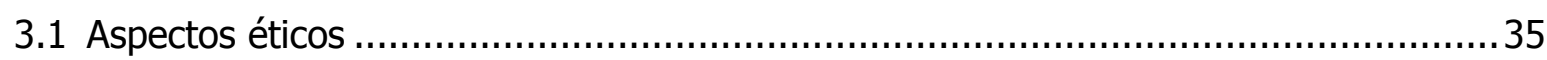

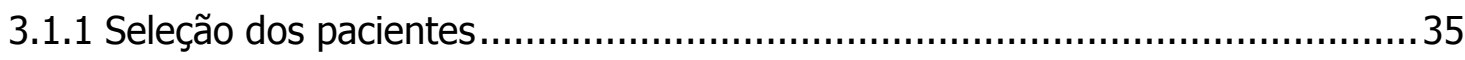

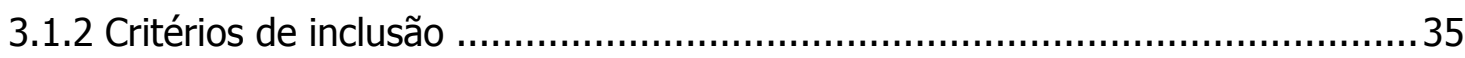

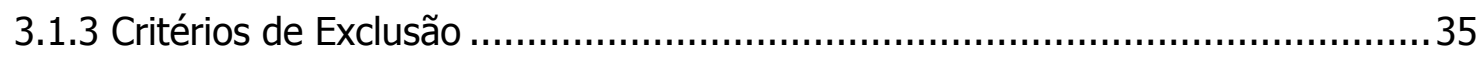

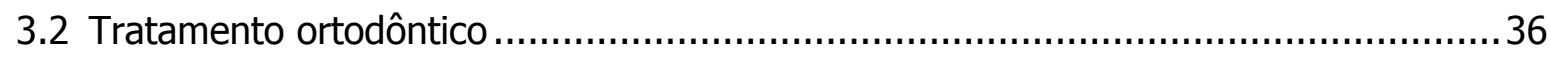

3.3 Coleta das células da mucosa bucal ........................................................40

3.4 Técnica de processamento e coloração das amostras ........................................4 41

3.5 Análise do Teste de micronúcleos (versão Cytome) ..........................................43

3.6 Análise Estatística............................................................................. 46

4. RESULTADOS $\ldots \ldots \ldots \ldots \ldots \ldots \ldots \ldots \ldots \ldots$

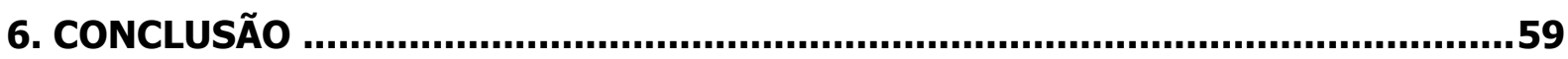

REFRÊNCIAS..................................................................................................63

ANEXO .................................................................................................................69 

1. Introdução 



\section{INTRODUÇÃO}

A mordida cruzada posterior é uma maloclusão definida como a posição reversa no plano transversal de um ou mais dentes maxilares (caninos, pré-molares e molares), com seus respectivos dentes antagonistas mandibulares, quando os arcos estão em relação cêntrica (Haas, 1961), podendo ser uni ou bi-lateral e classificada como dentária, óssea ou muscular (Haas, 1961; 1970; Pereira et al., 2017). Diferentes fatores estão provavelmente relacionados com a mordida cruzada posterior, incluindo respiração bucal, hábitos bucais deletérios, anomalias ósseas congênitas, discrepância dental negativa e do tamanho do arco, fissuras palatinas, perda precoce ou retenção prolongada de dentes decíduos, migração do germe do dente permanente e interferências oclusais (Graber, 1972; Pereira et al., 2017).

A Expansão Rápida da Maxila (ERM) é um método utilizado para a correção transversal da mordida cruzada posterior, por meio da abertura da sutura palatina mediana durante o período de crescimento esquelético, aplicando forças pesadas com aparatos rígidos e fixos para adquirir máxima resposta esquelética e mínimo movimento dentário (Haas, 1961; 1970; Weissheimer et al., 2011; Pereira et al., 2017).

Dentre os aparelhos utilizados para ERM, os dento-muco-suportados (disjuntor de Haas) e os dento-suportados (disjuntor de Hyrax) são os mais recomendados na literatura específica (Weissheimer et al., 2011). A principal diferença entre ambos é que, no disjuntor de Haas, é confeccionada uma placa de resina acrílica no aparelho, que permanece próxima ao palato do paciente. A função da placa de acrílico é aumentar a área de ancoragem do aparelho, proporcionando maior resposta do tecido ósseo e evitando possíveis recidivas pós-tratamento (Haas, 1961; 1970). Por outro lado, o disjuntor de Hyrax, por não apresentar o acrílico, facilita a higienização, prevenindo irritações dos tecidos moles decorrentes do acúmulo de resíduos (alimentos e biofilme) entre a mucosa e o acrílico (Biederman, 1968; Weissheimer et al., 2011; Bagatin et al., 2017). 


\subsection{Biodegração dos componentes dos aparelhos ortodônticos}

O meio bucal é particularmente ideal para a ocorrência da biodegradação de metais, devido às suas características químicas, térmicas, microbiológicas e enzimáticas (Kedici et al., 1998). Os disjuntores são confeccionados com acessórios à base de Níquel ( $\mathrm{Ni}$ ) e Cromo $(\mathrm{Cr})$ como parafusos expansores, fios metálicos e bandas metálicas, além da solda de prata, constituída de Prata $(\mathrm{Ag})$, Cobre $(\mathrm{Cu})$ e Zinco (Zn), utilizada para unir fios e bandas (Freitas et al., 2011). A liberação de íons metálicos decorrentes da corrosão dos componentes da aparelhagem fixa pode causar danos à mucosa bucal ou sensibilidade devido à sua toxicidade (Gonçalves et al., 2015). Acessórios ortodônticos fabricados com diferentes ligas metálicas foram avaliados como indutores de alterações genotóxicas, havendo evidências de que metais contendo Ni, Cobalto (Co), Cr e Berílio (Be) aumentam o risco de câncer em humanos (Martín-Cameán et al., 2015).

A resina acrílica utilizada no disjuntor de Haas é constituída de Monômero Metil Metacrilato (MMA), Tereftalato de dimetilo (DMT), Copolímero Metil EtilMetacrilato (PMMA), Peróxido e pigmentos. Além da resina acrílica, os disjuntores necessitam de materiais resinosos para serem fixados aos dentes que servirão de suporte. Tanto os compósitos quanto os cimentos resinosos apresentam bisfenol-A glicidil metacrilato (Bis-GMA), uretano dimetacrilato (UDMA) e trietileno glicol dimetacrilato (TEGDMA) como principais monômeros e co-monômeros em sua constituição (Siqueira Goncalves et al., 2008; Toy et al., 2014). Efeitos mutagênicos/genotóxicos e efeitos citotóxicos vem sendo associados com estes componentes (Lunder e Rogl-Butina, 2000; Schweikl et al., 2001; Toy et al., 2014).

Os estudos envolvendo a biocompatibilidade e citotocixidade de materiais odontológicos avaliam principalmente componentes como resina acrílica, compósitos, eláticos de látex e não látex e metais (Siqueira Goncalves et al., 2008; De Menezes e Quintão, 2010; Freitas et al., 2011; Maríez-Colomer et al., 2016). A avaliação da citotoxidade é o primeiro passo para o estudo da biocompatibilidade de materiais, pois refere-se à cascata de eventos moleculares que podem gerar funções celulares alteradas e danos estruturais (Murray et al., 2007; Martín-Cameán et al., 2015). Nesse sentido, o efeito mais perigoso da biodegradação que ocorre após a instalação de aparelhos ortodônticos na cavidade bucal é a possibilidade de gerar danos 
genotóxicos ao DNA de células humanas (Martín-Cameán et al., 2015). A genotoxicidade é a capacidade de um agente exercer efeitos deletérios ao material genético da célula, afetando sua integridade. Segundo Montanaro et al. (2005), a avaliação das propriedades genotóxicas dos metais utilizados no tratamento ortodôntico é essencial para determinar a segurança no uso desses materiais.

\subsection{Ensaios para avaliação da genotoxicidade}

Atualmente, existem vários métodos para avaliar o potencial genotóxico de agentes físicos e químicos, tais como Teste de Aberrações Cromossômicas, Troca entre Cromátides Irmãs, Reativação de Células Hospedeiras, Ensaio Cometa, Gamma-H2AX e o Teste de Micronúcleos (MNT) (Tatar et al., 2009; Ağar et al., 2011; Hafez et al., 2011; Öztürk et al., 2012; Yang et al., 2017) . Este último, considerado um dos melhores ensaios para avaliação de danos genéticos (Freitas et al., 2011), mensura danos cromossômicos produzidos por agentes clastogênicos (quebras nos cromossomos) ou aneugênicos (danos no fuso mitótico) (Gonçalves et al., 2015). Os micronúcleos (MN) são massas de cromatina citoplasmáticas aparentando forma de pequenos núcleos. São originários de quebras cromossômicas por fragmentos ou filamentos inteiros acêntricos (fora do centro). Estas quebras não são incorporadas ao núcleo principal celular durante a anáfase da divisão celular (Fenech et al., 2011).

O MNT pode ser realizado utilizando variadas técnicas, destacando-se a cultura de células (Gonçalves et al., 2014) e a citologia esfoliativa (Bonassi et al., 2011; Martín-Cameán et al., 2015). A utilização da citologia esfoliativa a partir de células da mucosa é relativamente simples e de baixo custo, quando comparada à cultura de células, o que permite a realização de estudos em âmbito populacional (Ayyad et al., 2006).

A versão Cytome é um método mais robusto do MNT. Como na versão original, produz resultados confiáveis dos danos ao DNA em nível cromossômico, (Gonçalves et al., 2015). Alterações nucleares degenerativas são avaliadas nessa versão, incluindo células binucleadas, brotos nucleares, cromatina condensada, cariorréxe, picnose e cariólise. A sensibilidade do MNT é aumentada quando estas 
anomalias são avaliadas conjuntamente com a frequência de MNs (Bonassi et al., 2007; Bonassi et al., 2011; Öztürk et al., 2012).

Poucos estudos avaliaram a genotoxicidade dos aparelhos ortodônticos, sendo a maioria referente a aparelhos corretivos (bráquetes, bandas, fios e compósitos) (Westphalen et al., 2008; Hafez et al., 2011; Öztürk et al., 2012; Toy et al., 2014; Gonçalves et al., 2015). Até o momento, os efeitos genotóxicos e citotóxicos dos disjuntores de Haas sobre células esfoliadas da mucosa bucal não foi investigado. Considerando a relevância clínica do assunto exposto, torna-se importante avaliar a influência local dos materiais utilizados para a confecção dos disjuntores de Haas, sobre os tecidos circundantes. 
2. Proposição 



\section{Proposição}

O objetivo deste estudo foi avaliar, in vivo, os efeitos genotóxicos e citotóxicos de disjuntores de Haas em células epiteliais esfoliadas da mucosa bucal de pacientes submetidos ao tratamento ortodôntico, por meio do teste de micronúcleos (versão Cytome). 

3. Material e Método 



\section{Material e Método}

\subsection{Aspectos éticos}

O projeto foi aprovado pelo Comitê de Ética em Pesquisa da Faculdade de Odontologia de Ribeirão Preto da Universidade de São Paulo (FORP/USP) (CAAE: 58659616.0.0000.5419) (Anexo A). A participação dos pacientes no estudo ocorreu de forma voluntária, com assinatura do Termo de Consentimento Livre e Esclarecido (TCLE) e Termo de Assentimento, por parte do participante ou responsável pelo paciente.

\subsubsection{Seleção dos pacientes}

Previamente ao estudo, foi adotado o alfa de $5 \%$ e o poder de $80 \%$ para o cálculo amostral. De acordo com os resultados apresentados por Gonçalves et al. (2015), a amostra estimada foi de 20 disjuntores. Assim, foram selecionados 28 pacientes que iniciaram tratamento ortodôntico na clínica de Graduação e Especialização em Ortodontia na Faculdade de Odontologia de Ribeirão Preto Universidade de São Paulo.

\subsubsection{Critérios de inclusão}

- Ambos os gêneros.

- 06 a 12 anos de idade.

- Sem distinção de etnia.

- Bom estado geral de saúde, verificado após anamnese detalhada.

- Presença de alterações transversais da maxila (mordida cruzada posterior).

- Ausência de restaurações ou próteses dentárias.

- Ausência de tratamento ortodôntico anterior.

\subsubsection{Critérios de Exclusão}

- Histórico de hipersensibilidade a metais (níquel e cromo), verificada após anamnese detalhada.

- Pacientes sindrômicos e portadores de problemas sistêmicos. 
- Pacientes diabéticos, anêmicos e com diagnóstico de câncer.

- Pacientes portadores de lesões de cárie com cavitação.

- Pacientes com doença periodontal.

- Pacientes portadores de doenças relacionadas a danos genéticos.

- Histórico de antibióticos e/ou bochechos com soluções antimicrobianas, no período de 3 meses previamente ao início do estudo.

\subsection{Tratamento ortodôntico}

O disjuntor de Haas foi utilizado para expansão rápida da maxila. Todos os princípios de confecção, fixação e ativação do aparelho foram seguidos, de acordo com as orientações preconizadas por Haas (1961), com adaptações para a dentição mista (Bagatin et al., 2017). O aparelho foi confeccionado com bandas de aço inoxidável (Dental Morelli, Sorocaba, SP, Brasil) nos $1^{\circ} \mathrm{S}$ molares permanentes, ligadas a fios de aço inoxidável de 0,9 mm de espessura (Dental Morelli, Sorocaba, SP, Brasil), contornando as faces vestibular e palatina dos caninos, molares decíduos e primeiro molar permanente. Os fios e bandas foram soldados entre si por fluxo e solda de prata (Dental Morelli, Sorocaba, SP, Brasil) aquecida com micro-maçarico (GB 2001, Blazer, Farmingdale, NY, USA), por vestibular e palatina.

Para confecção da placa de acrílico, foi utilizada resina acrílica autopolimerizável Ortoclass (Artigos Odontológicos Clássicos Ltda., São Paulo, Brasil) unindo as estruturas metálicas dos lados direito e esquerdo, com parafuso expansor de $11 \mathrm{~mm}$ (Dental Morelli, Sorocaba, SP, Brasil), centralizado transversalmente ao nível da sutura palatina mediana e ao nível dos segundos molares decíduos, no sentido ântero-posterior. Realizou-se o recorte e o acabamento do aparelho, utilizando broca Maxicut (Dental Future Systems, Ländenstrabe, Germany), seguida de broca de tungstênio (Artigos Odontológicos Clássicos Ltda., São Paulo, Brasil), em motor com peça de mão para baixa rotação (Dabi Atlante, Ribeirão Preto, SP, Brasil). Para acabamento e regularização da superfície, foram utilizadas lixas de madeira $n^{0}$ 180 e lixas d'água $n^{0} 400$ e 600 , montadas em mandris e motor de baixa rotação com peça de mão. $O$ polimento foi realizado com escova de pêlos em forma de roda, montada em torno para polimento, utilizando-se baixa velocidade e pasta de pedra- 
pomes em pó e água, seguida de uma roda de tecido. $\mathrm{O}$ aparelho foi lavado com água e sabão e o acabamento final foi realizado em polidora química (PQ 9000 Termotron, Piracicaba, SP, Brasil).

Após acabamento e polimento, o aparelho foi instalado com cimento de ionômero de vidro Ultra Band-Lok (Reliance Ortho Prod., Itasca, IL, USA) e os fios ortodônticos foram fixados nos caninos ou molares decíduos com resina composta universal Filtek $^{T M}$ Z350 XT (3M ESPE, Campinas, SP, Brasil) às faces vestibulares e palatinas. Os materiais utilizados para confecção, assim como os passos para a confecção, instalação e contenção pós-tratamento (Placa de Hawley) dos disjuntores de Haas estão apresentados na tabela 1 e nas figuras 1 , 2 e 3.

Tabela 1- Componentes utilizados nos disjuntores.

\begin{tabular}{|c|c|c|}
\hline Material & Composição & Fabricante \\
\hline Bandas de aço inoxidável & Níquel e Cromo & $\begin{array}{c}\text { Dental Morelli, Sorocaba, } \\
\text { SP, Brasil }\end{array}$ \\
\hline Fios de aço inoxidável & Níquel e Cromo & $\begin{array}{c}\text { Dental Morelli, Sorocaba, } \\
\text { SP, Brasil }\end{array}$ \\
\hline Parafuso expansor & Níquel e Cromo & $\begin{array}{c}\text { Dental Morelli, Sorocaba, } \\
\text { SP, Brasil }\end{array}$ \\
\hline Solda de prata & Prata, Cobre e Zinco & $\begin{array}{c}\text { Dental Morelli, Sorocaba, } \\
\text { SP, Brasil }\end{array}$ \\
\hline $\begin{array}{c}\text { Resina acrílica - pó } \\
\text { Resina acrílica - líquido }\end{array}$ & $\begin{array}{c}\text { Polimetilmetacrilato, Peróxido de } \\
\text { Benzoíla e Pigmentos } \\
\text { Metil Metacrilato e DMT }\end{array}$ & $\begin{array}{c}\text { Artigos Odontológicos } \\
\text { Clássicos Ltda., São Paulo, } \\
\text { Brasil }\end{array}$ \\
\hline Cimento resinoso & $\begin{array}{c}\text { Bis-GMA, Fibra de Vidro, Sílica } \\
\text { Amorfa e Fluoreto de Sódio }\end{array}$ & $\begin{array}{c}\text { Reliance Orthodontic } \\
\text { Products, Inc,. Itasca, IL, } \\
\text { USA }\end{array}$ \\
\hline Compósito & $\begin{array}{c}\text { Bis-GMA, UDMA, TEGDMA e Bis- } \\
\text { EMA }\end{array}$ & $\begin{array}{l}\text { Filtek }^{\mathrm{TM}} \text { Z350 XT (3M } \\
\text { ESPE, Campinas, SP, } \\
\text { Brasil) }\end{array}$ \\
\hline Resina flow & $\begin{array}{l}\text { Bis-GMA, Dimetacrilato, Boro- } \\
\text { Alumínio Silicato de Vidro, Sílica } \\
\text { Sintética, Pigmentos }\end{array}$ & $\begin{array}{c}\text { DFL, Rio de Janeiro, RJ, } \\
\text { Brasil }\end{array}$ \\
\hline
\end{tabular}


Figura 1- Confecção do aparelho disjuntor de Haas.

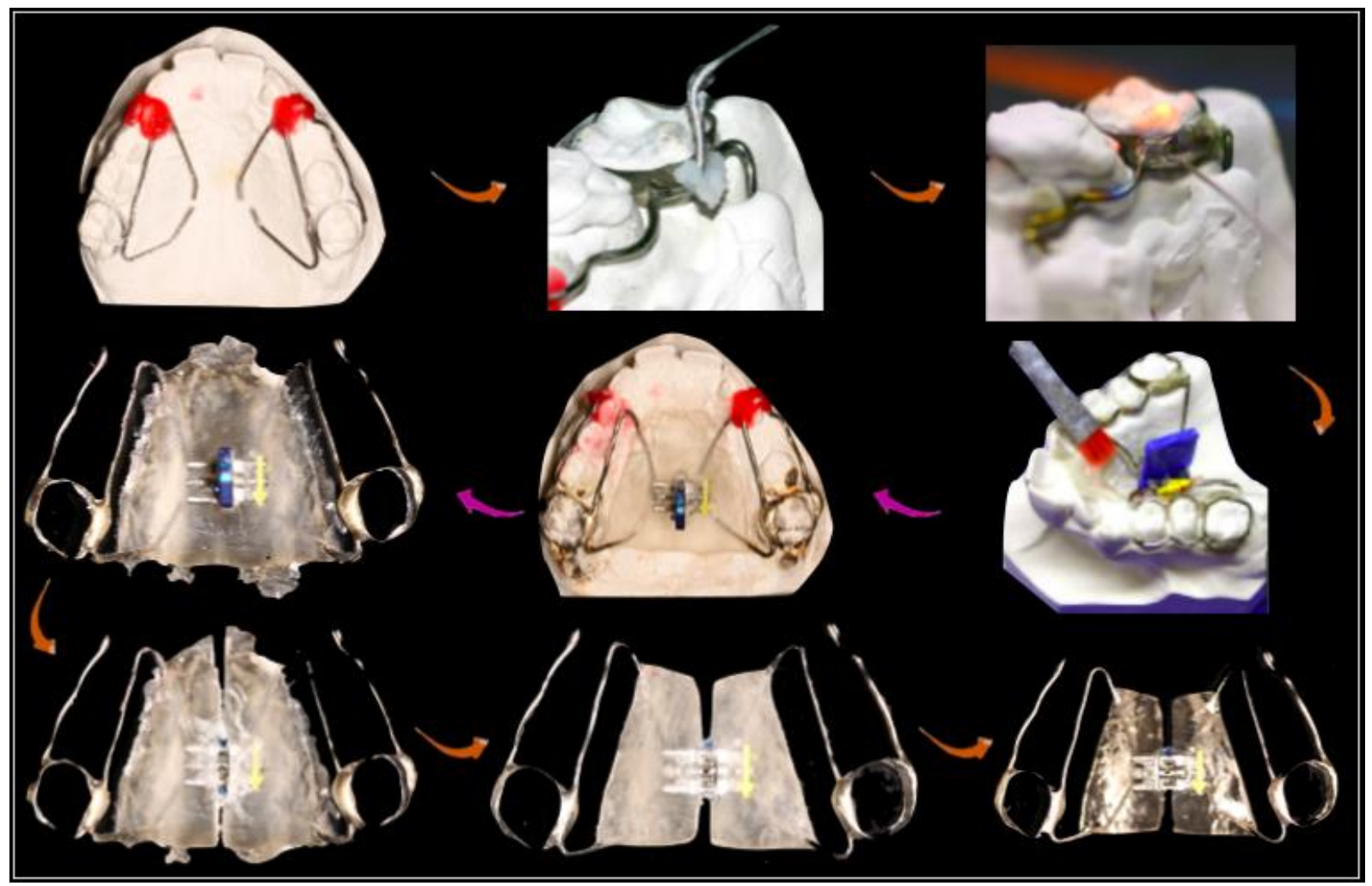

Figura 2 - Aparelho Disjuntor de Haas instalado. A. Aspecto intra-bucal frontal; B. Aspecto intra-bucal oclusal; e C e D. Aspecto intra-bucal lateral.

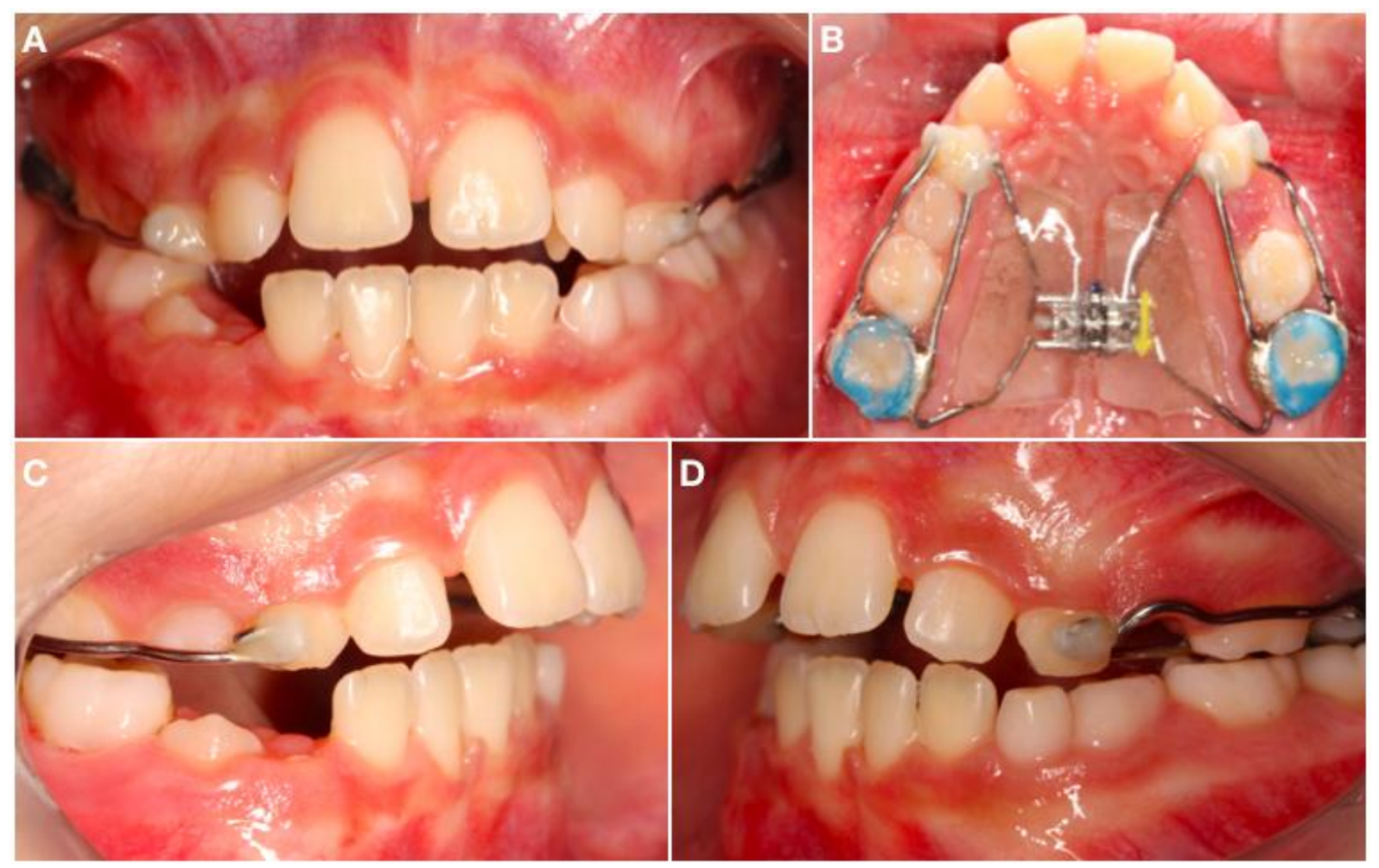


Previamente à instalação do aparelho, foi realizada tomada radiográfica oclusal. Após cimentação e fixação, o parafuso foi ativado seguindo as recomendações de Haas (1961). Primeiramente, quatro ativações (1/4 de volta) foram realizadas em intervalos de 15 minutos até completar $1,0 \mathrm{~mm}$ de expansão (uma volta completa) no dia da instalação. Nos dias seguintes, o responsável pelo paciente foi instruído a realizar $1 / 4$ de volta no período da manhã e $1 / 4$ de volta no período da noite, em intervalos de 12 horas. O controle clínico do paciente foi realizado semanalmente, até a obtenção da correção da mordida cruzada posterior, que ocorreu aproximadamente após 20 dias.

A ativação foi interrompida após comprovação da separação da sutura palatina mediana, visualizada após tomada de radiografia oclusal e, clinicamente, pela presença de diastema entre os incisivos centrais superiores e quando, no mínimo, as vertentes oclusais vestibulares das cúspides palatinas dos molares superiores estivessem em contato com as vertentes oclusais linguais das cúspides vestibulares dos molares inferiores. Após sobre-correção, o parafuso foi imobilizado com fio de amarrilho 0,012" (Dental Morelli, Sorocaba, SP, Brasil) e resina composta fluida Natural Flow (DFL, Rio de Janeiro, RJ, Brasil).

O disjuntor foi mantido na cavidade bucal do paciente, sem ativação, por um período mínimo de 3 meses após imobilização do aparelho, para reorganização das fibras e neoformação óssea na sutura palatina mediana (Haas, 1961). Ao final deste período, foi realizada tomada radiográfica oclusal para constatação da formação óssea na sutura palatina mediana, sendo o disjuntor removido. Em seguida, um aparelho de contenção removível foi instalado, composto por placa de resina autopolimerizável (Artigos Odontológicos Clássicos Ltda., São Paulo, Brasi), grampos tipo Adams ancorados nos molares e arco labial confeccionados de fios de aço inoxidável com 0,7 mm de espessura (Dental Morelli, Sorocaba, SP, Brasil). 
Figura 3 - Aparelho de contenção (Placa de Hawley). A. Aspecto intra-bucal frontal; B. Aspecto intra-bucal oclusal; e C e D. Aspecto intra-bucal lateral.

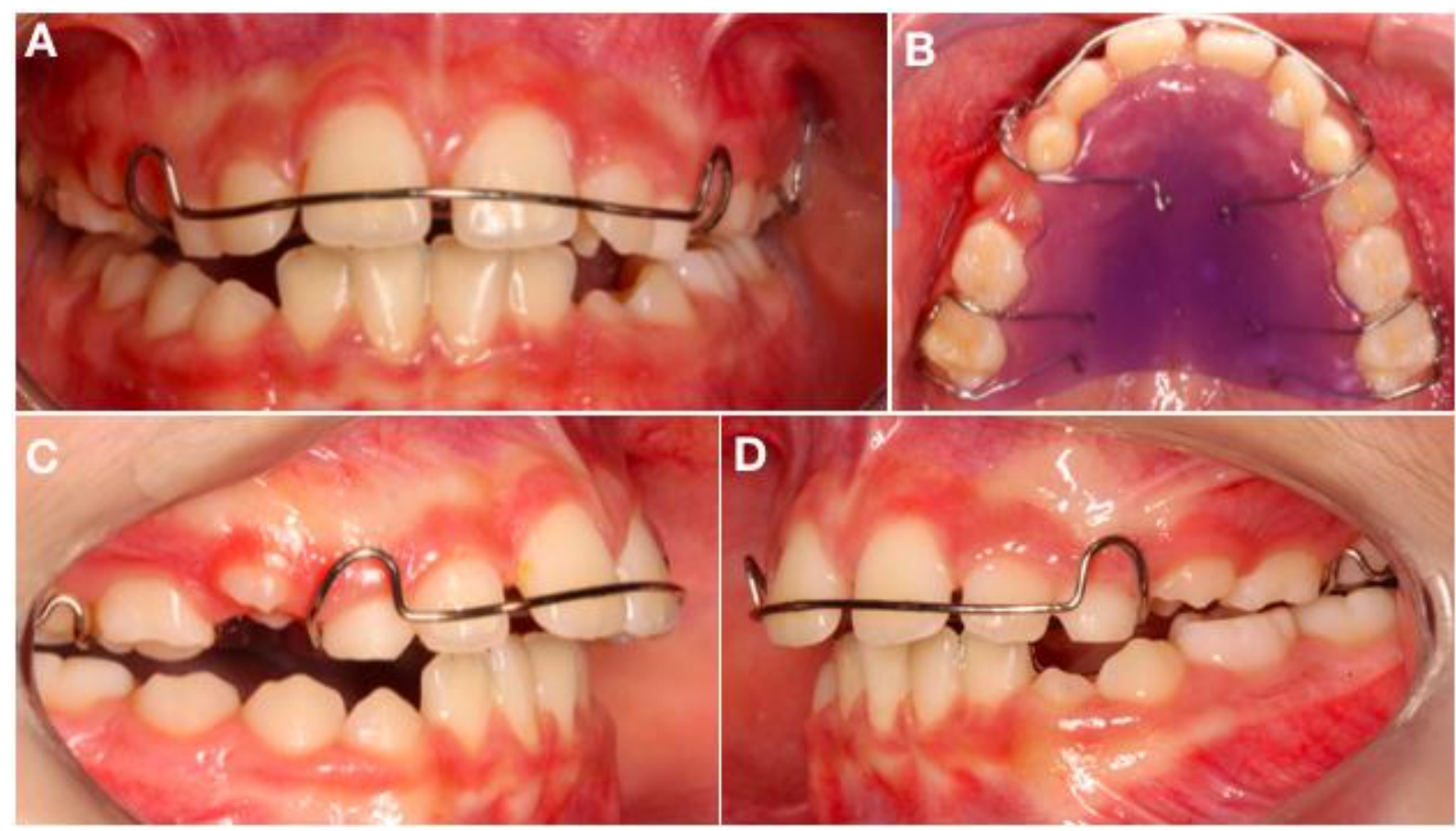

\subsection{Coleta das células da mucosa bucal}

A coleta das células da mucosa da bochecha foi realizada em três etapas: antes do tratamento (T0; baseline), após um mês (T1) e três meses após estabilização do aparelho (T2), utilizando escova dental macia (Escova Dental Cientifica; FORP-USP). Os participantes foram instruídos a bochechar soro fisiológico duas vezes durante 1 minuto antes da coleta, para remoção de células bucais descamadas. Em seguida, as células foram coletadas da região central dos lados direito e esquerdo da bochecha, por meio de raspagem suave com movimentos circulares de dentro para fora, durante 30 segundos (em média 20 rotações), para permitir a coleta homogênea das células do epitélio escamoso estratificado bucal. 0 material coletado foi transferido para tubos de polietileno de $15 \mathrm{~mL}$ tipo Falcon (Falcon, LMP, Kasui, China), não pirogênicos, livres de DNA, RNA, DNAse e RNAse e toxinas, devidamente identificados, contendo $5 \mathrm{~mL}$ de soro fisiológico. Os tubos foram mantidos em bolsas térmicas contendo gelo (aproximadamente $4^{\circ} \mathrm{C}$ ) sendo, em seguida, transportados imediatamente para o Laboratório de "Citogenética e Mutagênese" da Faculdade de Filosofia, Ciências e Letras de Ribeirão Preto - USP, para processamento das amostras (Figura 4). 
Figura 4 - Coleta das células da mucosa bucal.

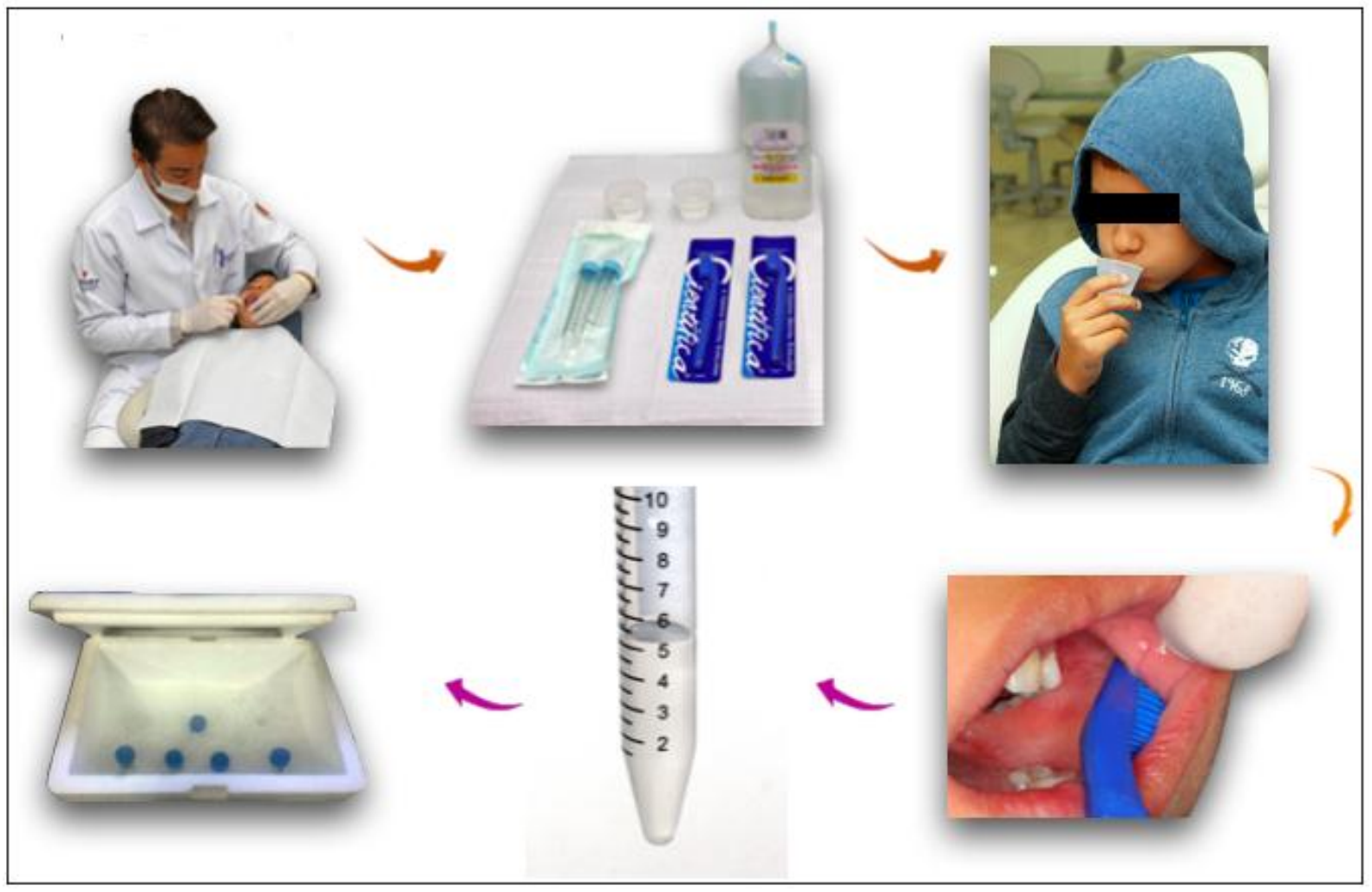

\subsection{Técnica de processamento e coloração das amostras}

O teste de micronúcleos versão Cytome foi realizado de acordo com o protocolo descrito por Tolbert et al. (1992) e Thomas et al. (2009). O processamento das amostras iniciou-se pela centrifugação dos tubos contendo as amostras a 1000 rpm, por 5 minutos. O sobrenadante foi retirado e descartado sendo, em seguida, acrescentados $5 \mathrm{~mL}$ de soro fisiológico ao pellet, para ressuspensão da amostra. Essa etapa de centrifugação foi realizada três vezes. Posteriormente, a solução fixadora (metanol/ácido acético 3:1) (Sigma-Aldrich, St. Louis, USA), contendo cinco gotas de Dimetil Sulfóxido (Sigma-Aldrich, St. Louis, USA) foi acrescentada. A suspensão foi agitada manualmente e novamente centrifugada, sendo o sobrenadante descartado. Esta etapa foi repetida duas vezes. Após nova etapa de ressuspensão, parte do sobrenadante foi retirada e descartada, deixando aproximadamente duas vezes 0 volume do sedimento de células. Após homogeneização, foram gotejadas (3 a 4 gotas) da suspensão em lâminas limpas e secas (Knittel Glass, Starfrost, Germany). As lâminas foram mantidas à temperatura ambiente por, no mínimo, 24 horas, para secagem (Figura 5). 
Figura 5 - Processamento das amostras.

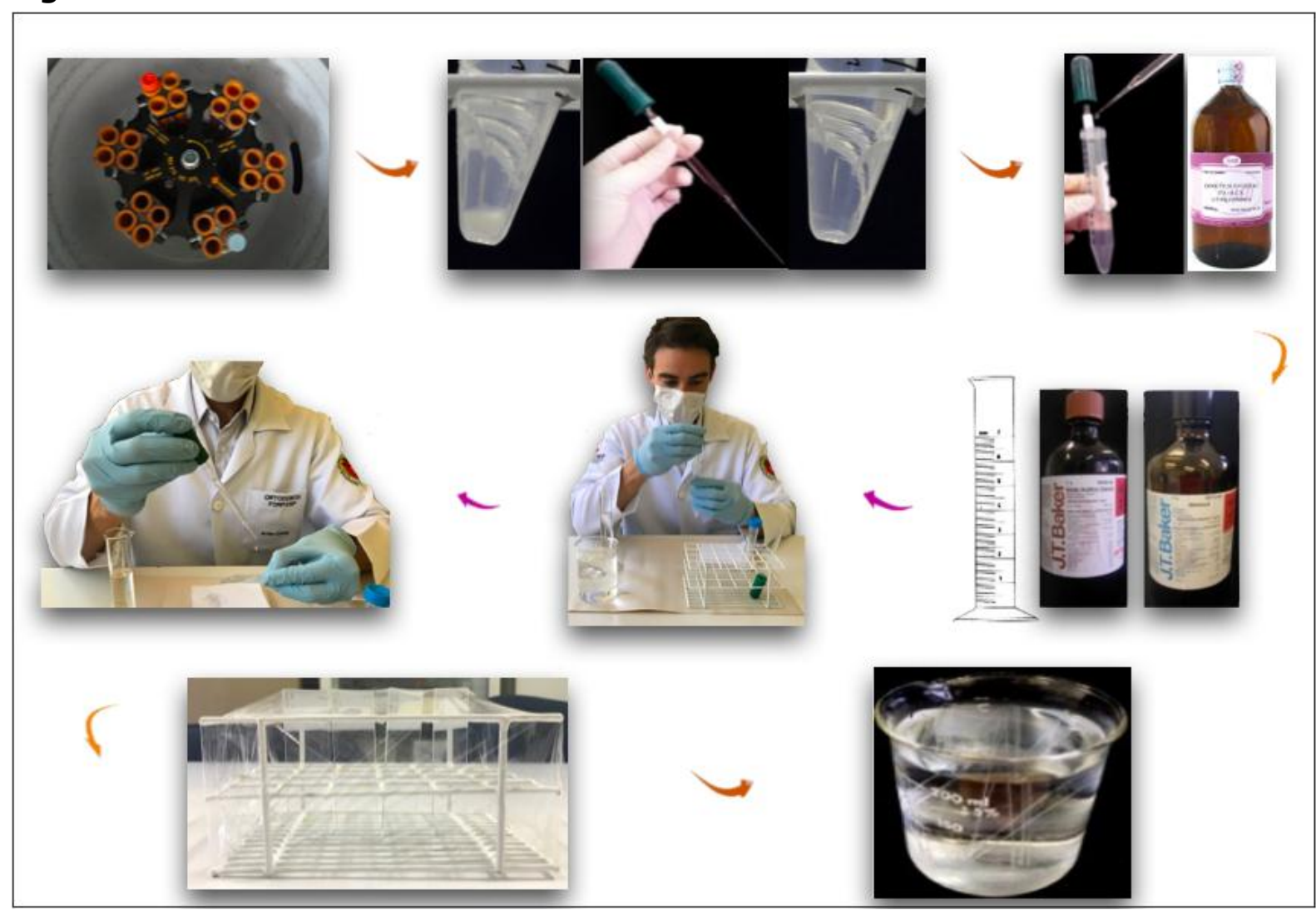

Para a coloração das amostras (Figura 6), o método de Feugen/Fast Green foi empregado. Primeiramente, as lâminas foram inseridas em cubetas contendo ácido hidroclorídrico ( $\mathrm{HCl} 5 \mathrm{~N}$, Labsynth-Diadema, SP, Brazil) por 20 minutos, e lavadas 3 vezes com água Milli-Q. As lâminas foram introduzidas, em outra cubeta envoltas em papel alumínio com o reativo de Schiff [ $1 \mathrm{~g}$ de fucsina básica, $200 \mathrm{~mL}$ de água destilada, $300 \mathrm{~mL}$ de $\mathrm{HCl} 1 \mathrm{~N}, 3 \mathrm{~g}$ de metabisulfito de potássio $\left(\mathrm{K}_{2} \mathrm{~S}_{2} \mathrm{O}_{5}\right)$ e $0,5 \mathrm{~g}$ de carbono descolorado], o qual foi mantido por 90 minutos, com agitação a cada 30 minutos. Decorrido esse período, foi acrescentada água destilada, por 10 minutos. As lâminas foram retiradas e secas à temperatura ambiente sendo, em seguida, contracoradas com Fast green a 3\% (95\% etanol e 0,25g Fast Green FCF - Merck Darmstadt, Germany), diluído em metanol a 100\% (Sigma-Aldrich, St. Louis, USA) para, posteriormente, serem analisadas microscopicamente. As células foram analisadas em microscópio óptico (microscópio binocular óptico, Carl Zeiss, Göttingen, Germany), com aumento de 400x. Para cada paciente foram confeccionadas duas lâminas. 
Figura 6 - Método de coloração das amostras.

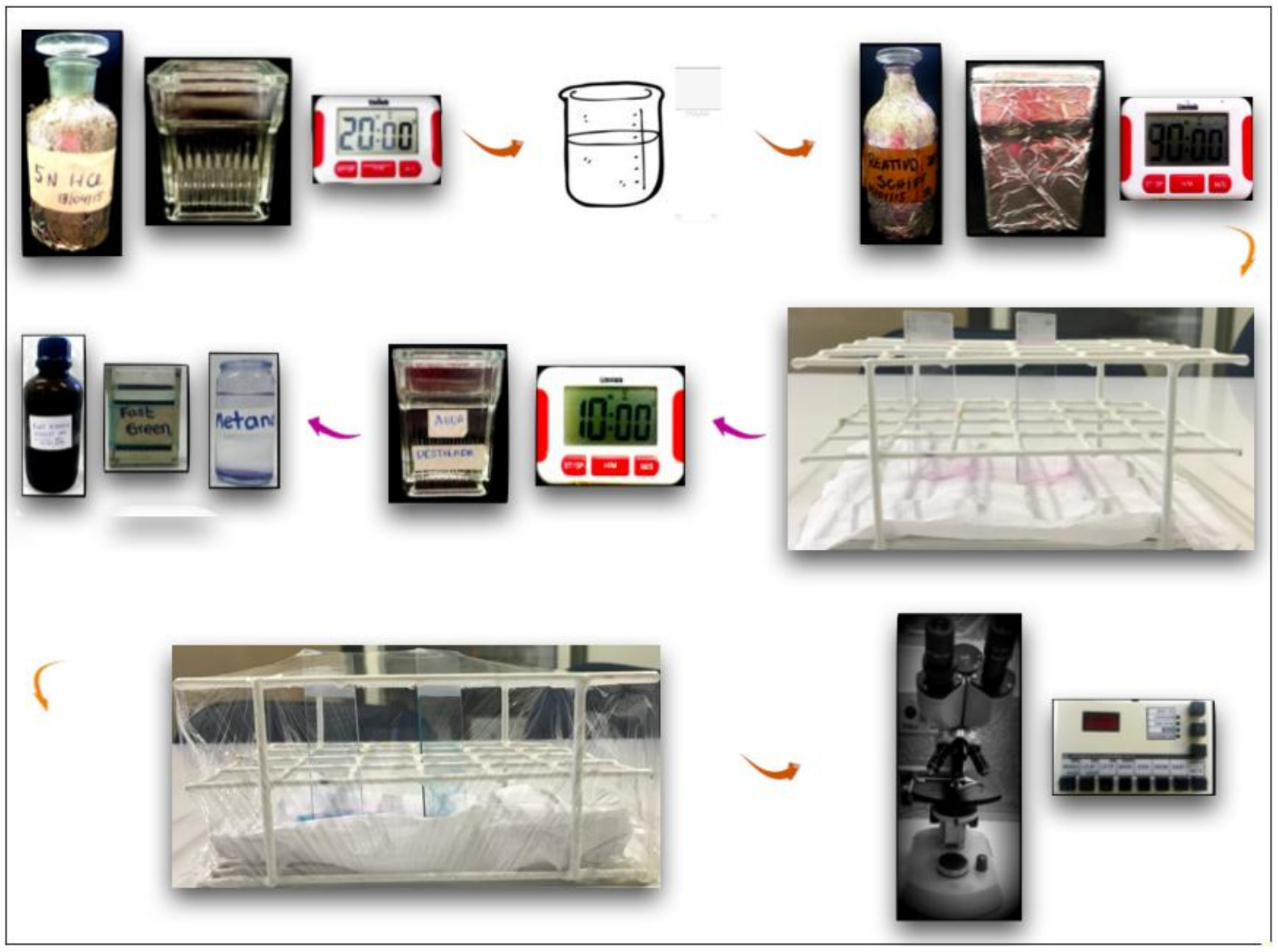

\subsection{Análise do Teste de micronúcleos (versão Cytome)}

Um único avaliador (A.C.S.) realizou a análise (duplo-cego) das lâminas, onde foram quantificadas 1000 células para caracterização das anormalidades celulares: células com danos ao DNA (micronúcleos e brotos nucleares), morte celular (cariólise e picnose) e defeitos citocinéticos (células binucleadas e trinucleadas). Para calibração do avaliador, pelo menos uma lâmina de cada período (T0, T1 e T2) foi analisada duas vezes pelo mesmo avaliador, em comparação a outro avaliador experiente (W.O.C.).

Os critérios de seleção das células para a contagem dos micronúcleos e das anormalidades celulares seguiram as recomendações descritas por Thomas et al. (2009), levando em consideração a atualização realizada pelos projetos de HUMN e HUMNXI (www.humn.org), onde foram acrescentados danos citogenéticos e outras anormalidades nucleares celulares ao MNT convencional. Foram considerados micronúcleos as estruturas que apresentaram um halo circundante sugestivo de uma 
membrana, com menos de 1/3-1/6 do diâmetro do núcleo com intensidade de coloração semelhante ao núcleo, no mesmo plano focal e com ausência de sobreposições ou pontes nucleares. Células picnóticas com MN não foram consideradas para a contagem de $\mathrm{MN}$, afim de evitar confusão com corpos apoptóticos de desintegração nuclear.

Como controle, foi efetuada a quantificação das células basais, que são células encontradas no epitélio da mucosa bucal. As características de cada célula analisada estão apresentadas na Tabela 2. A figura 7 (fluxograma) resume a metodologia empregada no presente estudo, para processamento das amostras, obtenção e análise das lâminas.

Tabela 2 - Descrição das células avaliadas.

\section{Tipos}

Células normais basais

\begin{tabular}{|c|c|c|}
\hline & & \\
\hline Picnose & $\begin{array}{l}\text { Células com condensação } \\
\text { irreversível de cromatina nuclear em } \\
\text { processo de apoptose. }\end{array}$ & $\begin{array}{l}\text { Núcleo pequeno } \\
\text { (encolhido) em } \\
\text { comparação às células } \\
\text { normais. }\end{array}$ \\
\hline Cariólise & $\begin{array}{c}\text { Estágio terminal de necrose e morte } \\
\text { celular. }\end{array}$ & $\begin{array}{l}\text { Resposta negativa nuclear } \\
\text { à coloração de Feulgen. } \\
\text { Célula com ausência de } \\
\text { núcleo (ghost-like). }\end{array}$ \\
\hline $\begin{array}{c}\text { Células } \\
\text { Bi(tri)nucleadas }\end{array}$ & $\begin{array}{l}\text { Células relacionadas à falha na } \\
\text { citocinese e possível atraso na } \\
\text { divisão celular. Provavelmente não } \\
\text { são relacionadas a alterações de } \\
\text { DNA }\end{array}$ & $\begin{array}{l}\text { Dois ou mais núcleos } \\
\text { principais de igual } \\
\text { tamanho, intensidade e } \\
\text { textura na mesma célula. }\end{array}$ \\
\hline Brotos nucleares & $\begin{array}{c}\text { Processo de eliminação de material } \\
\text { nuclear, pelo reparo de DNA ou DNA } \\
\text { amplificado. Podem ser precursores } \\
\text { dos MNs }\end{array}$ & $\begin{array}{l}\text { Estreita constrição de } \\
\text { parte do núcleo principal } \\
\text { originando um broto de } \\
\text { material nuclear. }\end{array}$ \\
\hline Micronúcleos & $\begin{array}{l}\text { Estruturas constituídas de material } \\
\text { cromatínico contido por um } \\
\text { envoltório nuclear e menores que o } \\
\text { núcleo principal. }\end{array}$ & $\begin{array}{l}\text { Apresentam-se de mesma } \\
\text { forma, textura e com } \\
\text { tamanho entre } 1 / 3 \text { e } 1 / 6 \\
\text { do núcleo principal. }\end{array}$ \\
\hline
\end{tabular}

\section{Características}

São as menores células

dentre as células esfoliadas bucais.

Núcleo pequeno (encolhido) em normais.

\section{Células encontradas na camada}

basal do epitélio.

Descriç̃̃o 
Figura 7 - Fluxograma dos procedimentos metodológicos.

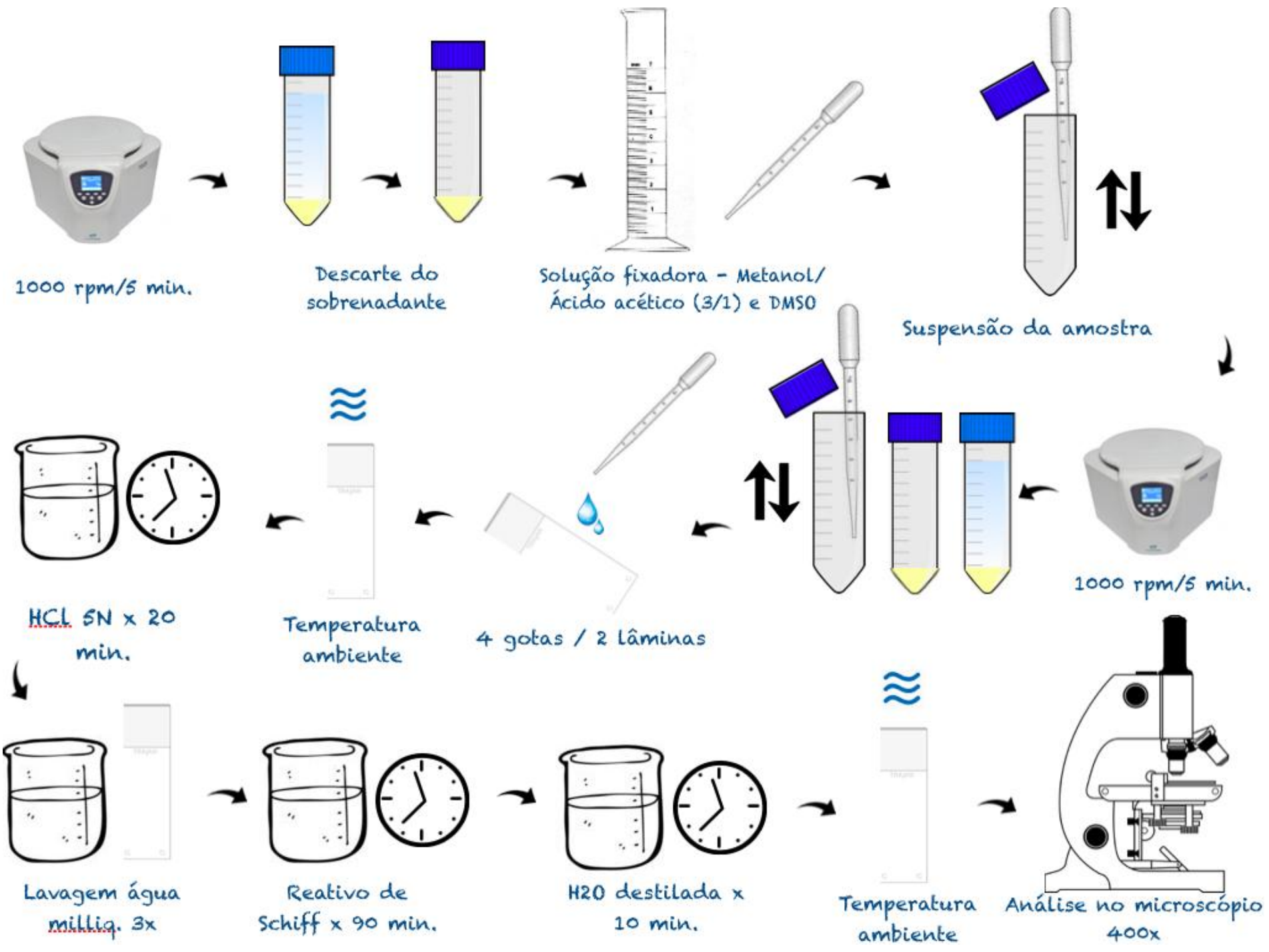




\subsection{Análise Estatística}

Os resultados foram analisados utilizando o software Graphpad Prism 7.0 para Mac (Graphpad Software Inc. USA), por meio do teste ANOVA seguido do pósteste de Tukey. O nível de significância adotado foi de 5\%. 
4. Resultados 



\section{Resultados}

A figura 8 ilustra imagens representativas do aspecto de células da mucosa bucal normais e de células com anormalidades.

Figura 8 - A e B. Células Basais Normais; C. Cariólise; D. Picnoses; E. Célula Bi-nucleada; F. Célula Tri-nucleada; G. Broto nuclear; H. Célula com um micronúcleo; I. Célula com dois micronúcleos.

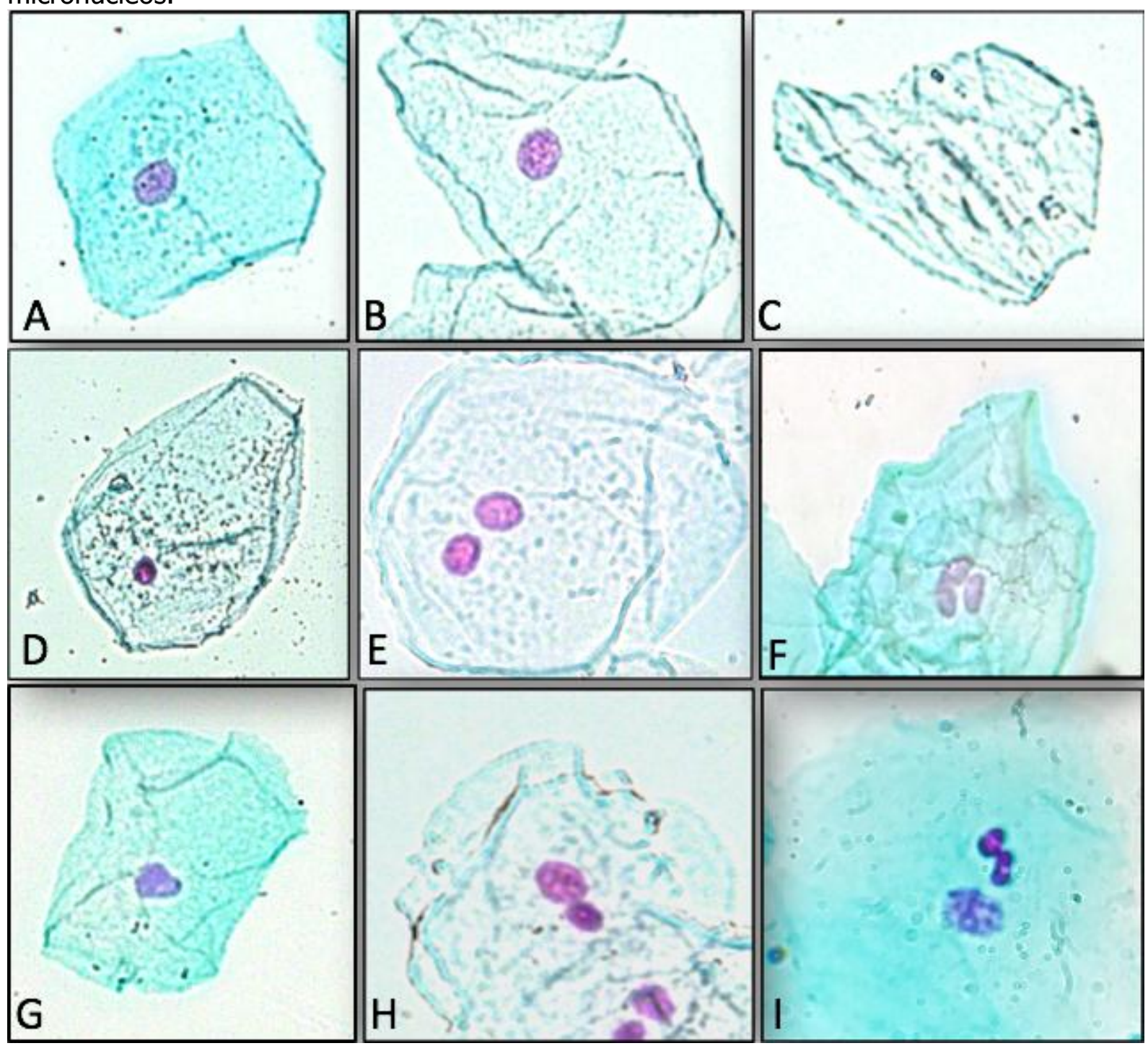


A tabela 3 apresenta a caracterização dos pacientes, sendo 60,7\% (17 pacientes) do sexo feminino e 39,3\% (11 pacientes) do sexo masculino. A idade média dos pacientes foi de 9 anos e 3 meses (DP 18,05 meses).

Tabela 3 - Características da amostra.

\begin{tabular}{l|l}
\multicolumn{2}{l}{$\begin{array}{l}\text { Pacientes }(\mathrm{n}=28) \\
\text { Gênero (\%) }\end{array}$} \\
\hline Masculino & 39,3 \\
\hline Feminino & 60,7 \\
\hline Ano (meses) & $9 a 3 \mathrm{~m}(18,05)$ \\
\hline Média (DP) & $82-143$ \\
\hline Variação &
\end{tabular}

Os resultados do MNT (danos genotóxicos e citotóxicos) nos diferentes períodos de avaliação (T1, T2 e T3) estão apresentados na Tabela 4 e na figura 9.

Tabela 4. Resultados do Teste de Micronúcleos, evidenciando a comparação entre os períodos de avaliação ( $\mathrm{T} 0=$ =antes do tratamento; T1=após um mês; e T1, três meses após estabilização do aparelho).

\begin{tabular}{c|c|c|c|c}
\hline \multirow{2}{*}{$\begin{array}{c}\text { Quantidade/1000 } \\
\text { células }\end{array}$} & \multicolumn{3}{|c|}{ Períodos avaliados } & \multirow{2}{*}{ p-valor } \\
\cline { 2 - 4 } & $\begin{array}{c}\text { T0 } \\
\text { Média (DP) }\end{array}$ & $\begin{array}{c}\text { T1 } \\
\text { Média (DP) }\end{array}$ & $\begin{array}{c}\text { T2 } \\
\text { Média (DP) }\end{array}$ & \\
\hline $\begin{array}{c}\text { Células } \\
\text { normais basais }\end{array}$ & $961,40(35,05) \mathrm{A}$ & $959,40(9,10) \mathrm{A}$ & $930,00(13,14) \mathrm{B}$ & $<0,0001$ \\
\hline Picnose & $1,17(1,13) \mathrm{A}$ & $3,50(2,18) \mathrm{B}$ & $6,96(4,52) \mathrm{C}$ & $<0,0001$ \\
\hline Cariólise & $11,46(3,09) \mathrm{A}$ & $16,39(5,72) \mathrm{B}$ & $27,46(8,05) \mathrm{C}$ & $<0,0001$ \\
\hline Células bi(tri)nucleadas & $10,07(3,72) \mathrm{A}$ & $15,39(4,81) \mathrm{B}$ & $31,89(7,01) \mathrm{C}$ & $<0,0001$ \\
\hline Broto nuclear & $0,71(1,21) \mathrm{A}$ & $3,50(2,23) \mathrm{B}$ & $1,71(1,21) \mathrm{A}$ & $<0,0001$ \\
\hline Micronúcleo & $0,85(0,84) \mathrm{A}$ & $1,71(1,56) \mathrm{A}$ & $1,75(1,32) \mathrm{A}$ & $>0,05$ \\
\hline DP = Desvio Padrão & & & &
\end{tabular}

Letras diferentes representam diferença estatisticamente significante entre os períodos. 
Figura 9 - Gráficos dos resultados obtidos nos diferentes períodos de avaliação (T0=antes do tratamento; T1=após um mês; e T1, três meses após estabilização do aparelho).

Normais

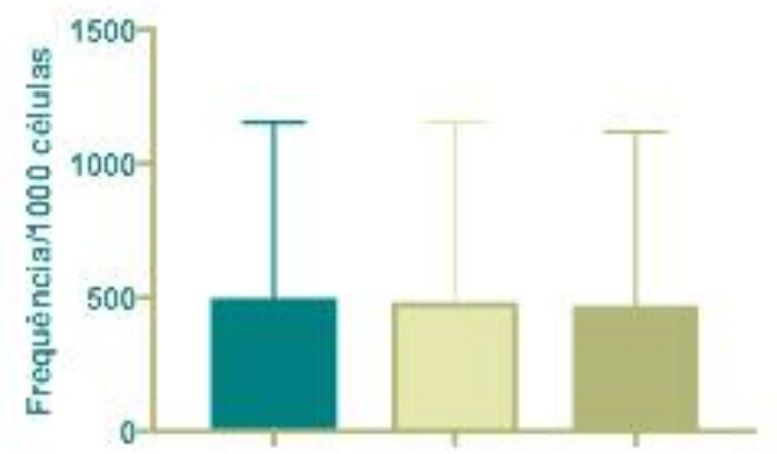

TO

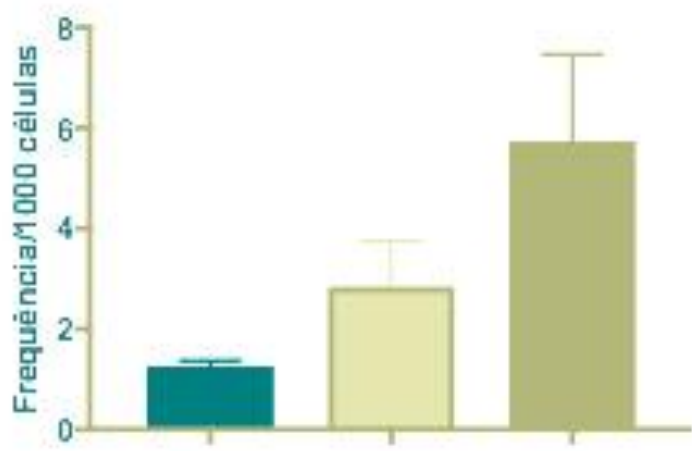

TO

T2

Cariólise

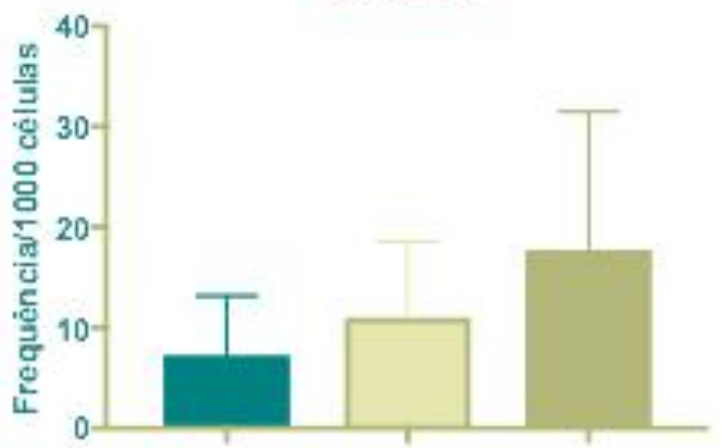

To T1

T2

$\mathrm{Bi}$ (Tri) nucleares

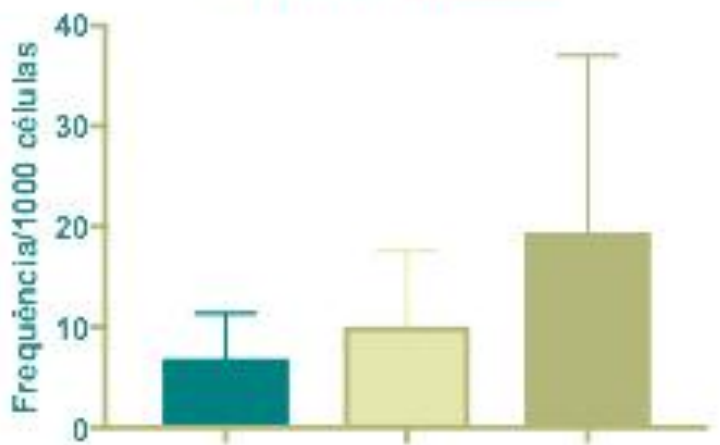

TO

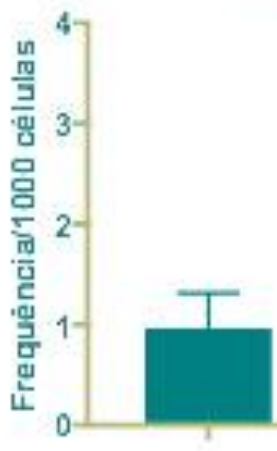

TO

$\mathrm{T} 1$

T2

Micronúcleos



To

T1

T2 
Com relação às células normais, não foi observada diferença significante quando comparou-se os períodos T0 e T1 ( $p>0.05)$. Entretanto, houve diferença estatisticamente significante $(p<0,05)$ no último período da coleta, com diminuição na quantidade de células.

Com relação aos Micronúcleos, não ocorreu aumento significante em nenhum dos períodos avaliados ( $p>0,05)$, embora tenha sido observada uma tendência de aumento quantitativo em T1 e T2.

Observou-se aumento estatisticamente significante $(p<0,05)$ na quantidade de células picnóticas, cariolíticas e bi/trinucleadas, nos períodos T1 e T2, em comparação a T0 (baseline).

As células bi/trinucleadas foram o tipo de alteração que sofreu o maior aumento numérico dentre todas as anormalidades avaliadas, seguido das células cariolíticas e das células picnóticas.

Ao contrário das outras células, o aumento das células com broto nuclear foi maior no primeiro mês de tratamento $(p<0,05)$, porém houve diminuição dos valores em T2. Comparando T0 e T2, o aumento dessa alteração não foi estatisticamente significante $(p>0,05)$. 


\section{Discussão}





\section{DiscusSÃo}

Para avaliação dos efeitos genotóxicos, o uso de um método de coloração específico de DNA é essencial, com intuito de evitar resultados falso-positivos. Elementos não nucleares, bactérias e grânulos de queratohialina podem ser confundidos e contabilizados como MN, quando métodos não-específicos de DNA são utilizados (Bolognesi et al., 2015). Embora diferentes métodos de coloração sejam utilizados para avaliação da genotoxicidade em células da mucosa bucal, o método de Feulgen/Fast Green, apesar de mais trabalhoso, é considerado o mais sensível para a mensuração de danos cromossômicos (Gonçalves et al., 2015).

Especificamente na área da Ortodontia, vários estudos avaliaram a genotoxicidade de aparelhos corretivos, contendo bráquetes, bandas, fios e compósitos, em células esfoliadas da cavidade bucal, empregando o MNT (Westphalen et al., 2008; Natarajan et al., 2011; Heravi et al., 2013; Toy et al., 2014; Francis et al., 2017). Deve ser ressaltado que esses estudos utilizaram diferentes métodos de coloração, incluindo Papanicolaou (Francis et al., 2017), Giemsa (Heravi et al., 2013) e Laranja de acridine (Toy et al., 2014). Além disso, os períodos de avaliação e os dispositivos ortodônticos utilizados não foram padronizados. Possivelmente, estes fatores geraram resultados conflitantes, sendo relatado aumento da média dos valores de MN por alguns autores (Westphalen et al., 2008; Natarajan et al., 2011; Francis et al., 2017), enquanto outros não verificaram diferenças (Angelieri et al., 2011; Heravi et al., 2013; Toy et al., 2014).

Utilizando o método de Felgen/Fast Green, no presente estudo não foi observada diferença estatisticamente significante na média dos valores de MN nos diferentes períodos de avaliação, durante o tratamento ortodôntico com disjuntores de Haas, embora tenha ocorrido uma tendência ao aumento quantitativo de MNs. Esses resultados são similares aos obtidos por Gonçalves et al. (2015), que utilizaram o mesmo método de coloração empregado no presente estudo, para avaliar o efeito genotóxico de disjuntores de Hyrax. Esses autores relataram uma tendência ao aumento da média dos valores de $\mathrm{MN}$ no primeiro mês de tratamento. Seis meses após, os valores tenderam a diminuir e, após um ano, curiosamente tenderam a sofrer novo aumento, atingindo valores similares aos observados no primeiro mês. À 
semelhança do que ocorreu no presente estudo, esses autores não observaram diferença significante entre os períodos, evidenciando que a significância clínica e biológica dessas alterações permanece incerta.

Vale a pena ressaltar que, de acordo com Thomas et al. (2009), pacientes mais jovens apresentam menores índices de $\mathrm{MN}$, o que justifica a necessidade da realização de estudos adicionais, avaliando as alterações genotóxicas, em pacientes com idades mais avançadas. No presente estudo, a idade dos pacientes foi homogênea, sendo a amostra composta por crianças entre 6-12 anos, o que possivelmente justifica a ausência de danos genotóxicos pelo MNT. Pela idade dos participantes, supõe-se que não houve ingestão de nicotina e/ou bebidas alcoólicas.

No presente estudo, 3 avaliações (T0, T1 e T2) foram realizadas em cada paciente, ou seja, cada paciente foi considerado seu próprio controle. Assim, fatores relacionados à dieta alimentar e exposição a ambientes radioativos, supostamente, foram controlados. Portanto, qualquer efeito de outros agentes genotóxicos/citotóxicos deveria estar presente na primeira coleta de células (T0), e quaisquer diferenças entre as avaliações subsequentes podem ser atribuídas aos possíveis danos do disjuntor de Haas, em contato com a mucosa bucal.

Com relação à citotoxicidade, no presente estudo os valores encontrados para as células picnóticas e cariolíticas aumentaram estatisticamente em T1 e T2. Resultados semelhantes foram observados por Gonçalves et al. (2015), que avaliaram disjuntores de Hyrax. Segundo esses autores, a causa desse aumento estaria relacionada com os componentes da solda de prata, em contato com a cavidade bucal. $\mathrm{O}$ calor requerido durante a soldagem certamente aumenta a taxa de corrosão do dispositivo (Gonçalves et al., 2015). Além disso, o cobre presente na liga de prata promove maiores liberações de íons metálicos tóxicos, como o níquel, na região de solda (Wataha et al., 2000). Segundo Ramirez e Saldanha (2002), o aumento de células cariolíticas representa uma resposta adaptativa a traumas no epitélio bucal e está relacionado com células necróticas e danos citotóxicos. Esta anomalia é normal na região da mucosa da bochecha, especialmente em decorrência da mastigação. Entretanto, a ação constante de agentes mutagênicos como álcool, tabaco, radioterapia e, possivelmente, aparelhos ortodônticos, poderia aumentar 0 índice de morte celular, caracterizado pelo aumento significativo desta anomalia 
celular, como pôde ser observado no presente estudo, durante o uso de disjuntores de Haas. Vale a pena ressaltar que, segundo alguns autores, danos citotóxicos podem ocasionar a morte de células portadoras de MNs, diminuindo a observação e quantificação dessa anormalidade genotóxica (Angelieri et al., 2010; Lorenzoni et al., 2012), o que pode possivelmente explicar a ausência de aumento estatisticamente significante na contagem de MNs no presente trabalho (com uso de disjuntor de Haas) e no trabalho de Gonçalves et al., (2015), que avaliou disjuntores de Hyrax.

A ocorrência de células binucleadas foi a anormalidade que apresentou os maiores valores no presente estudo, com média superior a 30/1000 células, em T2. Estas células são indicativas de falhas na citocinese, associada a doenças neurodegenerativas e células cancerígenas, sugerindo que uma alta proporção dessas células pode estar associada com a taxa de risco a essas lesões (Thomas et al., 2007).

Adicionalmente, o presente estudo demonstrou aumento significante das células com formação de brotos nucleares em T1. Entretanto, em T2 a média dos valores tornaram-se similares aos encontrados antes da inserção do disjuntor de Haas. Gonçalves et al. (2015) observaram padrão similar após 6 meses de tratamento com o disjuntor de Hyrax. A formação de brotos nucleares pode ser um possível biomarcador diretamente relacionado ao dano do genoma por quebras de DNA relacionado à liberação de íons metálicos (Fenech et al., 2011) sendo, possivelmente, um antecessor da formação de Mns (Mitchell e Norman, 1987).

O disjuntor de Haas, aparelho ortodôntico avaliado no presente estudo, é composto por uma placa de resina acrílica, materiais metálicos soldados por solda de prata, fios aderidos ao sistema resinoso e bandas cimentadas com cimento resinoso, o que pode levar à hipótese de que esses componentes, individualmente ou em combinação, causam danos celulares quando o aparelho permanece em contato com a mucosa bucal. Para comprovação da citotoxidade de cada componente presente no aparelho disjuntor de Haas, são necessários mais estudos.

Outro fator importante é que, em comparação com o tratamento ortodôntico corretivo, os disjuntores de Haas permanecem em contato com a cavidade bucal por períodos mais curtos. Embora no presente trabalho tenham sido observados efeitos citotóxicos em células esfoliadas da cavidade bucal (cerca de três meses), os estudos 
que avaliaram outros dispositivos ortodônticos por períodos de tempo mais longos (entre 6 a 9 meses) (Öztürk et al., 2012; Toy et al., 2014; Gonçalves et al., 2015) evidenciaram que a citotoxicidade é maior nos períodos iniciais. Há evidências de rápida liberação de monômeros residuais, nas primeiras 24horas, a partir de resinas ortodônticas, sendo os íons metálicos liberados apenas nos estágios iniciais do tratamento ortodôntico (Martín-Cameán et al., 2015).

Além disso, as células epiteliais da mucosa bucal regeneram-se rapidamente, geralmente a cada 7 a 14 dias (Öztürk et al., 2012). Em outras palavras, os efeitos genotóxicos/citotóxicos dos dispositivos ortodônticos podem não permanecer a longo prazo, sendo reversíveis (Baraba et al., 2011; Martín-Cameán et al., 2015). No entanto, os efeitos citotóxicos e genotóxicos iniciais devem ser considerados em pacientes geneticamente predispostos a danos genotóxicos adicionais, dependendo do estilo de vida de cada indivíduo (Angelieri et al., 2011).

Outro fator a ser considerado é que os disjuntores de Haas podem, clinicamente, ser associados ao uso de DATs (dispositivos de ancoragem temporária), arcos linguais ou aparelhagem fixa corretiva, que podem permanecer em contato com as células da cavidade bucal por meses ou até por anos (Ortiz et al., 2011; Martín-Cameán et al., 2015; Choi et al., 2017). A exposição repetida a agentes citotóxicos/genotóxicos pode resultar em lesão celular crônica, proliferação celular compensatória, hiperplasia e desenvolvimento de tumores (Lorenzoni et al., 2012).

No presente estudo, observou-se que os disjuntores de Haas, embora não tenham ocasionado aumento de micronúcleos nas células da mucosa bucal, aumentaram a ocorrência de células cariolíticas, picnóticas e bi/trinucleadas, o que sugere possíveis efeitos citotóxicos. A fim de reduzir esses efeitos indesejáveis, as pesquisas na área da Ortodontia deveriam focar, também, no desenvolvimento de novos materiais, menos susceptíveis à biodegradação e com menor liberação de componentes prejudiciais. Além disso, sugere-se a realização de estudos adicionais, com inclusão de pacientes com maior faixa etária avaliando, inclusive, se essas alterações citotóxicas e genotóxicas se mantêm, após a remoção dos aparelhos ortodônticos. 
6. Conclusão 



\section{ConclusÃo}

Com base na metodologia empregada e nos resultados obtidos, concluiu-se que os disjuntores de Haas não ocasionaram aumento de micronúcleos em células da mucosa bucal. Entretanto, células cariolíticas, picnóticas e bi/trinucleadas foram observadas durante o tratamento, sugerindo possíveis efeitos citotóxicos. 

Referências 



\section{REFERÊNCIAS}

1. Ağar G, Aslan A, Sarioğlu EK, Alpsoy L, Çeker S. Protective activity of the methanol extract of Usnea longissima against oxidative damage and genotoxicity caused by aflatoxin B_1 in vitro. Turk J Med Sci. 2011;41(6):1043-9.

2. Angelieri F, Carlin V, Martins RA, Ribeiro DA. Biomonitoring of mutagenicity and cytotoxicity in patients undergoing fixed orthodontic therapy. Am J Orthod Dentofacial Orthop. 2011;139(4):e399-e404.

3. Angelieri F, Carlin V, Saez D, Pozzi R, Ribeiro DA. Mutagenicity and cytotoxicity assessment in patients undergoing orthodontic radiographs. Dentomaxillofac Rad. 2010;39(7):437-40.

4. Ayyad SBA, Israel E, El-Setouhy M, Nasr GR, Mohamed MK, Loffredo CA. Evaluation of Papanicolaou stain for studying micronuclei in buccal cells under field conditions. Acta cytol. 2006;50(4):398-402.

5. Bagatin CR, Andrucioli MCD, Ferreira JTL, Matsumoto MAN, da Silva RAB, da Silva LAB. Biofilm formation in Haas palatal expanders with and without use of an antimicrobial agent: an in situ study. Microsc res tech. 2017;80(5):471-7.

6. Baraba A, Želježić D, Kopjar N, Mladinić M, Anić I, Miletić I. Evaluation of cytotoxic and genotoxic effects of two resin-based root-canal sealers and their components on human leucocytes in vitro. Int Endod J. 2011;44(7):652-61.

7. Biederman W. A hygienic appliance for rapid expansion. J Pract Orthod. $1968 ; 2(2): 67-70$.

8. Bolognesi C, Bonassi S, Knasmueller S, Fenech M, Bruzzone M, Lando C, et al. Clinical application of micronucleus test in exfoliated buccal cells: A systematic review and metanalysis. Mutat Res Rev Mutat Res. 2015;766:20-31.

9. Bonassi S, Coskun E, Ceppi M, Lando C, Bolognesi C, Burgaz S, et al. The HUman MicroNucleus project on eXfoLiated buccal cells (HUMN XL): the role of life-style, host factors, occupational exposures, health status, and assay protocol. Mutat Res Rev Mutat Res. 2011;728(3):88-97.

10. Bonassi S, Znaor A, Ceppi M, Lando C, Chang WP, Holland N, et al. An increased micronucleus frequency in peripheral blood lymphocytes predicts the risk of cancer in humans. Carcinogenesis. 2007;28(3):625-31.

11. Choi HW, Park YS, Chung SH, Jung MH, Moon W, Rhee SH. Comparison of mechanical and biological properties of zirconia and titanium alloy orthodontic micro-implants. Korean J Orthod. 2017;47(4):229-37.

12. De Menezes LM, Quintão CCA, editors. The release of ions from metallic orthodontic appliances. Semin Orthod; 2010: Elsevier. 
13. Dindaroğlu F, Doğan S. Evaluation and comparison of root resorption between tooth-borne and tooth-tissue borne rapid maxillary expansion appliances: A CBCT study. Angle Orthod. 2015;86(1):46-52.

14. Fenech M, Kirsch-Volders M, Natarajan A, Surralles J, Crott J, Parry J, et al. Molecular mechanisms of micronucleus, nucleoplasmic bridge and nuclear bud formation in mammalian and human cells. Mutagenesis. 2011;26(1):125-32.

15. Francis $P$, Thomas $M$, Antony $V$, Shaloob $M$, Hassan $K J$, Roshan $G$. Cytomorphometric analysis on the effects of components of orthodontic appliances on the epithelial cells of the buccal mucosa. J Int Soc Prevent Communit Dent. 2017;7(3):142.

16. Freitas MP, Oshima HM, Menezes LM. Release of toxic ions from silver solder used in orthodontics: an in-situ evaluation. Am J Orthod Dentofacial Orthop. 2011;140(2):177-81.

17. Garib DG, Henriques JFC, Janson G, de Freitas MR, Fernandes AY. Periodontal effects of rapid maxillary expansion with tooth-tissue-borne and tooth-borne expanders: a computed tomography evaluation. Am J Orthod Dentofacial Orthop. 2006;129(6):749-58.

18. Garrett BJ, Caruso JM, Rungcharassaeng K, Farrage JR, Kim JS, Taylor GD. Skeletal effects to the maxilla after rapid maxillary expansion assessed with cone-beam computed tomography. Am J Orthod Dentofacial Orthop. 2008;134(1):8. e1-8. e11.

19. Gonçalves TS, de Menezes LM, Trindade C, da Silva Machado M, Thomas $\mathrm{P}$, Fenech $\mathrm{M}$, et al. Cytotoxicity and genotoxicity of orthodontic bands with or without silver soldered joints. Mutat Res-Gen Tox En. 2014;762:1-8.

20. Gonçalves TS, Menezes LM, Trindade C, Thomas P, Fenechc M, Henriques JA. In vivo evaluation of the genotoxic effects of Hyrax auxiliary orthodontic appliances containing silver-soldered joints. Mutat Res-Genet Tox En. 2015;791:25-9.

21. Graber T. Orthodontics: principles and practice (ed. 3) WB Saunders Company. Philadelphia; 1972.

22. Haas AJ. Palatal expansion: just the beginning of dentofacial orthopedics. Amer J Orthodontics. 1970;57(3):219-55.

23. Haas AJ. Rapid expansion of the maxillary dental arch and nasal cavity by opening the midpalatal suture. Angle Orthod. 1961;31(2):73-90.

24. Hafez HS, Selim EMN, Eid FHK, Tawfik WA, Al-Ashkar EA, Mostafa YA. Cytotoxicity, genotoxicity, and metal release in patients with fixed orthodontic appliances: a longitudinal in-vivo study. Am J Orthod Dentofacial Orthop. 2011;140(3):298-308. 
25. Heravi F, Abbaszadegan MR, Merati M, Hasanzadeh N, Dadkhah E, Ahrari F. DNA damage in oral mucosa cells of patients with fixed orthodontic appliances. J denti (Tehran). 2013;10(6):494.

26. Kedici S, Aksüt AA, Kílíçarslan MA, Bayramog Lu G, Gökdemir K. Corrosion behaviour of dental metals and alloys in different media. J Oral Rehabil. 1998;25(10):800-8.

27. Lorenzoni DC, Fracalossi ACC, Carlin V, Ribeiro DA, Sant'Anna EF. Mutagenicity and cytotoxicity in patients submitted to ionizing radiation: A comparison between cone beam computed tomography and radiographs for orthodontic treatment. Angle Orthod. 2012;83(1):104-9.

28. Lunder T, Rogl-Butina M. Chronic urticaria from an acrylic dental prosthesis. Contact Dermatitis. 2000;43(4):232-3.

29. Martín-Cameán A, Jos Á, Mellado-García P, Iglesias-Linares A, Solano E, Cameán AM. In vitro and in vivo evidence of the cytotoxic and genotoxic effects of metal ions released by orthodontic appliances: A review. Environ toxicol phar. 2015;40(1):86-113.

30. Martínez-Colomer S, Gaton-Hernández P, Romano FL, De Rossi A, Fukada SY, Nelson-Filho P. Latex and nonlatex orthodontic elastics: In vitro and in vivo evaluations of tissue compatibility and surface structure. Angle Orthod. 2016;86(2):278-84.

31. Mitchell JC, Norman A. The induction of micronuclei in human lymphocytes by low doses of radiation. Int J Radiat Biol Relat Stud Phys Chem Med. 1987;52(4):527-35.

32. Montanaro L, Cervellati M, Campoccia D, Prati C, Breschi L, Arciola CR. No genotoxicity of a new nickel-free stainless steel. Int J Artif Organs, v. 28, n. 1, p. 58-65, 2005. ISSN 0391-3988.

33. Murray PE, García Godoy C, García Godoy F. How is the biocompatibilty of dental biomaterials evaluated? Med Oral Patol Oral. 2007;12(3):258-66.

34. Natarajan M, Padmanabhan S, Chitharanjan A, Narasimhan M. Evaluation of the genotoxic effects of fixed appliances on oral mucosal cells and the relationship to nickel and chromium concentrations: an in-vivo study. Am J Orthod Dentofacial Orthop. 2011;140(3):383-8.

35. Ortiz AJ, Fernandez E, Vicente A, Calvo JL, Ortiz C. Metallic ions released from stainless steel, nickel-free, and titanium orthodontic alloys: toxicity and DNA damage. Am J Orthod Dentofacial Orthop. 2011;140(3):e115-22.

36. Öztürk F, Yüksel Ş, Toy E, Kurtoglu EL, Küçük EB. Genotoxic effects of banding procedure with different orthodontic cements on human oral mucosa cells. Turk J Med Sci. 2012;42(Sup. 1):1157-65. 
37. Pereira JdS, Jacob HB, Locks A, Brunetto M, Ribeiro GLU. Evaluation of the rapid and slow maxillary expansion using cone-beam computed tomography: a randomized clinical trial. Dental Press J Orthod. 2017;22(2):61-8.

38. Ramirez A, Saldanha PH. Micronucleus investigation of alcoholic patients with oral carcinomas. Genet Mol Res. 2002;1(3):246-60.

39. Schweikl H, Schmalz G, Spruss T. The induction of micronuclei in vitro by unpolymerized resin monomers. J Dent Res. 2001;80(7):1615-20.

40. Siqueira Goncalves T, Minghelli Schmitt V, Thomas M, Lopes de Souza MA, Macedo de Menezes L. Cytotoxicity of two autopolymerized acrylic resins used in orthodontics. Angle Orthod. 2008;78(5):926-30.

41. Tatar A, Özkurt Z, HacimÜFtÜOĞLu A, YeŞi̇Lyurt A, Vancelik S. Evaluation of ribavirin genotoxicity with sister chromatid exchange and micronuclei assays in humans. Turk J Med Sci. 2009;39(2):241-6.

42. Thomas P, Hecker J, Faunt J, Fenech M. Buccal micronucleus cytome biomarkers may be associated with Alzheimer's disease. Mutagenesis. 2007;22(6):371-9.

43. Thomas P, Holland N, Bolognesi C, Kirsch-Volders M, Bonassi S, Zeiger E, et al. Buccal micronucleus cytome assay. Nat protoc. 2009;4(6):825-37.

44. Toy E, Yuksel S, Ozturk F, Karatas $\mathrm{OH}$, Yalcin M. Evaluation of the genotoxicity and cytotoxicity in the buccal epithelial cells of patients undergoing orthodontic treatment with three light-cured bonding composites by using micronucleus testing. Korean J Orthod. 2014;44(3):128-35.

45. Wataha J, Lockwood P, Schedle A. Effect of silver, copper, mercury, and nickel ions on cellular proliferation during extended, low-dose exposures. J Biomed Mater Res A. 2000;52(2):360-4.

46. Weissheimer A, de Menezes LM, Mezomo M, Dias DM, de Lima EM, Rizzatto SM. Immediate effects of rapid maxillary expansion with Haastype and hyrax-type expanders: a randomized clinical trial. Am J Orthod Dentofacial Orthop. 2011;140(3):366-76.

47. Westphalen G, Menezes L, Prá D, Garcia G, Schmitt V, Henriques J, et al. In vivo determination of genotoxicity induced by metals from orthodontic appliances using micronucleus and comet assays. Genet Mol Res. 2008;7(4):1259-66.

48. Yang Y, He X, Shi J, Hickel R, Reichl F-X, Högg C. Effects of antioxidants on DNA double-strand breaks in human gingival fibroblasts exposed to dental resin co-monomer epoxy metabolites. Dent Mater J. 2017;33(4):418-26. 
Anexo 



\title{
ANEXO
}

\author{
UNIVERSIDADE DE SÃO PAULO \\ FACULDADE DE ODONTOLOGIA DE RIBEIRÃO PRETO \\ Comitê de Ética em Pesquisa
}

Atest.CEP 009/2017

ATESTADO

Atestamos, de acordo com os registros desta Secretaria, que o Protocolo CAAE no 58659616.0.0000.5419 sobre a pesquisa intitulada "AVALIAÇÃO IN VIVO DOS EFErTOS GENOTÓXICOS EM CÉLULAS EPITELIAIS DA MUCOSA E DA LIBERAÇÃO DE ÍONS EM PACIENTES ORTODÔNTICOS TRATADOS COM DISJUNTORES DE HAAS", SOb a responsabilidade de Arthur Cunha da Silva, fol aprovado pelo Comitê de Ética em Pesquisa da Faculdade de Odontologia de Ribeirão Preto, Universidade de São Paulo, em 01/09/2016.

We hereby certify, in accordance with the existing settlements of this Office, that the Protocolo CAAE no 58659616.0.0000.5419 about the research entitled "GENOTOXIC AND CYTOTOXIC EFFECTS OF HASS APPLIANCE IN EXFOLIATED BUCCAL MUCOSA CELLS DURING ORTHODONTIC TREATMENT", under responsibility of . Dr. Arthur Cunha da Silva, was approved by the Research Ethics Committee of the School of Dentistry of Ribeirão Preto, University of São Paulo, Brazil, in 01/09/2016.

Ribeirão Preto, 30 de outubro de 2017.

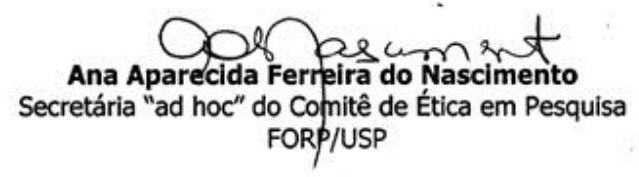

